\title{
Modelagem da transferência de calor de ambientes subterrâneos no programa de simulação EnergyPlus
}

\author{
Modelling of basement heat transfer in EnergyPlus \\ simulation program
}

\section{Bruna Cristina Resende Henor Artur de Souza Adriano Pinto Gomes}

\section{Resumo \\ 1}

temperatura do solo é um dos fatores mais influentes nas avaliações de desempenho térmico de ambientes subterrâneos e quase sempre é desconsiderada. Por isso, é necessário avaliar essa influência devido à interação do solo com a edificação, pois a transferência de calor através de paredes e pisos subterrâneos tem uma extensão significativa na carga térmica total de uma edificação. Este trabalho compara e avalia o impacto de diferentes alternativas de modelagem presentes no programa de simulação EnergyPlus por meio da análise das trocas de calor entre o solo, o piso e as paredes de um ambiente subterrâneo de uma edificação unifamiliar de São Paulo, Brasil, não condicionada artificialmente e não isolada termicamente. A comparação das alternativas de modelagem por meio da análise recomendada pela NBR 15575 indicou grande variação nos resultados de temperatura interna do ambiente subterrâneo da edificação. Quando comparado ao pré-processador Basement, os modelos do objeto GroundDomain apresentaram variação de temperatura interna do ambiente subterrâneo de até $6{ }^{\circ} \mathrm{C}$ no verão e de $5,2^{\circ} \mathrm{C}$ no inverno. Tais resultados fornecem indicações da influência e da variabilidade que o uso das diferentes opções de modelagem do EnergyPlus podem gerar em uma análise de desempenho térmico.

Palavras-chave: Desempenho térmico. EnergyPlus. Pré-processador Basement. Objeto GroundDomain. Simulação computacional. Cômodos subterrâneos.

\begin{abstract}
Soil temperature is one of the most influential factors in the evaluation of the thermal performance of underground environments, but it is almost always disregarded. Thus, it is necessary to evaluate this influence due to the interaction of the soil with the building, since heat transfer through subterranean walls and floors has a significant extension in the total thermal load of a building. This study compares and evaluates the impact of different modelling alternatives present in

the EnergyPlus simulation program by analysing the heat exchanges between the soil, the floor and the walls of a basement of a single-story building in São Paulo, Brazil, not artificially conditioned and not insulated thermally. The comparison between the modelling alternatives through the analysis recommended by NBR 15575 indicated a large variation in the internal temperature results of the underground building environment. When compared with Basement preprocessor, the models of the object GroundDomain presented an internal temperature variation of the basement up to $6{ }^{\circ} \mathrm{C}$ in the summer and up to $5.2{ }^{\circ} \mathrm{C}$ in the winter. These results offer indications of the influence and variability that the use of the different modelling options present in EnergyPlus program can generate in a thermal performance analysis.
\end{abstract}

${ }^{1}$ Bruna Cristina Resende ${ }^{1}$ Universidade Federal de Ouro Preto Ouro Preto - MG - Brasil

${ }^{2}$ Henor Artur de Souza ${ }^{2}$ Universidade Federal de Ouro Preto Ouro Preto - MG-- Brasil

${ }^{3}$ Adriano Pinto Gomes ${ }^{3}$ Instituto Federal de Minas Gerais Ouro Preto - MG - Brasil

Recebido em 28/02/18 Aceito em 05/06/18
Keywords: Thermal performance. EnergyPlus. Basement pre-processor. Object GroundDomain. Computer simulation. Basements. 


\section{Introdução}

Com o aprimoramento das técnicas construtivas nos pavimentos superiores de uma edificação, a transferência de calor através de ambientes subterrâneos tornou-se uma fração mais significativa da perda de calor e do consumo de energia total da edificação (CLEMENTS, 2004). Dessa forma, a necessidade de otimizar o desempenho térmico, principalmente em função da racionalização do consumo de energia nas últimas décadas, estimulou o desenvolvimento de modelos computacionais para melhor explicar a transferência de calor proveniente do contato direto do solo com os ambientes subterrâneos de uma edificação. Alguns desses modelos são integrados em pacotes de simulação de edificações, tais como o EnergyPlus, um programa de simulação numérica de carga térmica e análise energética validado pela ASHRAE 140 (AMERICAN..., 2014) e utilizado como programa oficial do Departamento de Energia dos Estados Unidos para simulações de edificações que buscam a eficiência energética. No Brasil, a norma NBR 15575 (ABNT, 2013) recomenda que as simulações computacionais do desempenho térmico das edificações também sejam executadas também no programa EnergyPlus.

No software EnergyPlus (DEPARTMENT..., 2016a) a transferência de calor de ambientes subterrâneos pode ser calculada com o auxílio do pré-processador Basement (DEPARTMENT..., 2016b) para gerar resultados mais precisos (DEPARTMENT..., 2016d), ou de forma mais simplificada, por meio do objeto GroundDomain (DEPARTMENT..., 2016c). O método de cálculo utilizado pelo pré-processador Basement utiliza basicamente as formulações desenvolvidas por Bahnfleth (1989) e Cogil (1998) (ANDOLSUN et al., 2011). Já o método de simulação do GroundDomain conta com três procedimentos distintos de simulação: FiniteDifference (XING, 2014; LEE, 2013; HERB et al., 2008), Kusuda \& Achenbach (KUSUDA; ARCHENBACH, 1965) e Xing (XING, 2014).

No Brasil, a preocupação com o desempenho mínimo das edificações ganhou espaço em anos recentes (SORGATO et al., 2014). Como os ambientes subterrâneos de edificações familiares são comumente usados como espaços habitáveis, eles devem estar condicionados a atender aos mesmos critérios de conforto térmico que os demais ambientes do pavimento superior de uma edificação (CLEMENTS, 2004). Uma forma documental de estabelecer os requisitos mínimos de desempenho, vida útil e de garantia para os principais sistemas que compõem as edificações residenciais é a norma NBR 15575 (SORGATO et al., 2014). Segundo
Silva et al. (2014), a NBR 15575 (ABNT, 2013) representa um avanço para o setor da construção civil no Brasil, caracterizando-se como um passo importante para a qualidade das edificações e seu desempenho nas diversas vertentes. A norma estabelece requisitos referentes ao desempenho das edificações, representado por níveis mínimos de desempenho, os quais devem ser obrigatoriamente atendidos, e por esse motivo é amplamente adotada nas avaliações de desempenho térmico de edificações.

Em cômodos subterrâneos com pisos e paredes de concreto não isolados, Labs et al. (1988) descobriram que a perda de calor em edificações de baixa elevação pode contribuir em até $60 \%$ das perdas totais quando o pavimento superior é bem isolado. Krarti (1999) verificou que a análise da transferência de calor envolvendo o solo tem um efeito significativo nas avaliações de desempenho térmico de edificações familiares e comerciais térreas, chegando a contribuir com até $30 \%$ do total das cargas de aquecimento e arrefecimento da edificação. Clements (2004) analisou os efeitos da modificação da condutividade térmica do solo para averiguar a influência do solo no desempenho térmico de uma edificação modelo. Para isso, ele considerou três cidades dos Estados Unidos com variados climas. A suposição de um solo arenoso quando a condição real é de um solo argiloso resultou em uma subestimação entre $50 \%$ e $80 \%$ das perdas de calor médias anuais de um ambiente subterrâneo da edificação analisada. Kharrufa (2008) realizou uma avaliação de desempenho térmico em uma edificação de Bagdá sem isolamento térmico e com ventilação natural para analisar o uso de ambientes subterrâneos no período de verão. O ambiente subterrâneo da edificação analisada é constituído por paredes de tijolo, piso de blocos de concreto e laje de concreto, com 2,5 m de profundidade abaixo do nível do solo e 1,0 m acima do solo. Os resultados medidos para um dia crítico do verão indicaram que, enquanto a temperatura externa do ar atingiu o valor máximo de $43{ }^{\circ} \mathrm{C}$, a temperatura do ambiente subterrâneo atingiu o valor máximo de $35^{\circ} \mathrm{C}$.

Andolsun et al. (2011) quantificaram as diferenças entre os modelos de transferência de calor existentes nos programas de simulação DOE-2 e EnergyPlus/Basement por meio da análise de um ambiente subterrâneo para uma edificação modelo situada no Texas, EUA. Segundo esses autores, em edifícios térreos as perdas e ganhos de calor devido ao contato de paredes e pisos com o solo apresentam valores significativos no desempenho térmico de uma edificação. O cômodo subterrâneo 
termicamente isolado da edificação modelo foi testado para duas configurações distintas: condicionado e não condicionado artificialmente. Os resultados revelaram que a simulação no EnergyPlus resultou em acréscimo entre 3\% e 23\% de resfriamento e em redução de $12 \%$ a $29 \%$ de aquecimento quando comparado à simulação executada no programa DOE-2.

Mais recentemente, Costa, Roriz e Chvatal (2017) compararam diferentes alternativas de modelagem nos programas EnergyPlus/GroundDomain e EnergyPlus/Slab dos parâmetros relacionados à transferência de calor entre o piso e o solo e sua influência no desempenho térmico de uma edificação térrea naturalmente ventilada localizada em São Carlos, Brasil. A comparação das alternativas de modelagem indicou que o uso do Slab pode causar diferenças significativas nos resultados. Entre estas, a maior variação alcançada foi obtida entre o método KusudaAchenbach do objeto GroundDomain e o Slab, com diferença de 55,2\% no número de horas de desconforto térmico.

Os resultados obtidos por Andolsun et al. (2011) e Costa, Roriz e Chvatal (2017) revelam que a utilização de diferentes alternativas de modelagem para a obtenção do fluxo de calor entre a edificação e o solo pode gerar grande impacto nas avaliações de desempenho térmico para ambientes não isolados. No entanto, as pesquisas existentes até o momento, já citadas, analisam em especial os ambientes subterrâneos que são isolados termicamente e condicionados artificialmente. No Brasil, onde as casas são usualmente ventiladas naturalmente e não possuem isolamento térmico no piso e nas paredes, há a necessidade de mais estudos que abordem o tema. Nesse contexto se insere esta pesquisa, cujo objetivo é avaliar o impacto das diferentes alternativas de modelagem existentes no programa EnergyPlus em relação às trocas de calor entre o solo, o piso e as paredes de um ambiente subterrâneo de uma edificação unifamiliar, não condicionada artificialmente e não isolada termicamente. As análises da influência da interação do solo com a edificação são realizadas por meio do método de simulação da norma NBR 15575 (ABNT, 2013), com a avaliação de dias típicos de projeto de verão e de inverno.

\section{Métodos de simulação no EnergyPlus}

Atualmente, as edificações que possuem ambientes em contato com o solo podem ser simuladas no EnergyPlus por três modos distintos:

(a) com o objeto

GroundTemperature:BuildingSurface - as instruções e advertências quanto ao uso desse procedimento de simulação encontram-se no Input/Output Manual (DEPARTAMENT..., 2016e);

(b) com o objeto GroundDomain:Basement - as orientações para a utilização desse procedimento de simulação encontram-se no Input/Output Manual (DEPARTAMENT..., 2016e); e

(c) com o objeto Detailed Ground Heat Transfer por meio do pré-processador Basement - as instruções básicas de uso do programa e a descrição de suas variáveis de entrada e de saída encontram-se no Auxiliary Programs Manual (DEPARTAMENT..., 2016d).

O primeiro método consiste em informar apenas a temperatura média mensal da superfície do solo no objeto GroundTemperature:BuildingSurface. Esse método é geralmente adotado quando o usuário não possui os dados de entrada necessários sobre o ambiente subterrâneo da edificação e as propriedades termofísicas do solo no entorno da edificação. Contudo, esse método de simulação é uma forma simplificada, em que a influência do solo não é considerada. Nesse caso, os dados sobre a temperatura do solo são geralmente obtidos pelos arquivos climáticos utilizados para simular a edificação e não representam a situação real do solo no local analisado. Para analisar a influência do solo de forma precisa é necessário obter as propriedades termofísicas do solo no local analisado, pois o solo sofre variação por diversos fatores, como a quantidade de água presente em seus vazios, a profundidade da edificação e as condições de cobertura no entorno da edificação.

Nos demais procedimentos de simulação (Basement e GroundDomain:Basement), o programa calcula a temperatura da interface entre o solo, as paredes e a laje dos ambientes subterrâneos da edificação, que posteriormente é utilizada como dados de entrada para o EnergyPlus prosseguir com o restante da simulação. A principal diferença entre esses dois procedimentos de simulação é que a temperatura do solo, no pré-processador Basement, é obtida de forma tridimensional, enquanto no GroundDomain realizam-se algumas aproximações para o cálculo da temperatura do solo ser obtido de forma unidimensional.

\section{GroundDomain: Basement (GDomain)}

O GDomain é capaz de lidar com diferentes configurações de isolamento térmico a partir de um modelo em diferenças finitas implícito, capaz de fornecer as temperaturas não perturbadas do solo de forma unidimensional (DEPARTAMENT..., 2016c). As temperaturas não perturbadas equivalem 
às temperaturas que o solo apresentaria caso não estivesse sendo “perturbado" por algo como, por exemplo, uma edificação. Quando adicionado, o GDomain é acionado automaticamente pelo programa. Os modelos de temperaturas não perturbadas do solo existentes no programa são os seguintes.

(a) KusudaAchenbach: este objeto fornece as temperaturas não perturbadas do solo com base na pesquisa desenvolvida por Kusuda e Achenbach (1965). Esse método utiliza como parâmetros a temperatura média do solo na superfície, a amplitude da temperatura do solo na superfície e o dia do ano no qual a temperatura da superfície atinge o valor mínimo; desse modo, o método é capaz de definir uma correlação para as temperaturas não perturbadas do solo em função da profundidade e do tempo;

(b) FiniteDifference: este objeto utiliza um modelo em diferenças finitas para obter a transferência de calor no solo. Um arquivo climático é utilizado para obter as condições de contorno da superfície do solo. Inicialmente, é executada a simulação anual do modelo até que o perfil de temperatura anual do solo alcance um comportamento periódico constante. Uma vez que esse comportamento de equilíbrio é atingido, as temperaturas do solo são armazenadas e utilizadas durante o restante da simulação da edificação. A base para o modelo é fundamentada nos conceitos desenvolvidos por Xing (2014), e os métodos numéricos são adaptados aos modelos descritos em Lee (2013). Já as condições de contorno do equilíbrio térmico da superfície do solo são semelhantes às descritas em Herb et al. (2008); e

(c) Xing: método mais complexo, que exige um maior número de variáveis de entrada (MAZZAFERRO; MELO; LAMBERTS, 2015) e é capaz de fornecer as temperaturas não perturbadas do solo com base na correlação desenvolvida por Xing (2014). A correlação é composta de cinco parâmetros (média anual da temperatura do solo na superfície, duas amplitudes da temperatura do solo na superfície e dois ângulos de fase da temperatura do solo) e um modelo de dois harmônicos. Os dados fornecidos pelo arquivo climático do local analisado é utilizado para obter as condições de contorno da superfície.

O método KusudaAchenbach é a opção mais conveniente quando o usuário possui apenas as informações sobre as propriedades termofísicas do solo e as características construtivas do ambiente subterrâneo, uma vez que o programa é capaz de calcular os demais dados de entrada com as informações obtidas pelo arquivo climático do local analisado. No entanto, assim como ocorre para o método de simulação GroundTemperature:BuildingSurface, essas informações obtidas pelo arquivo climático não representam a situação real do solo no local da edificação em estudo e podem comprometer os resultados da simulação. Os métodos de simulação FiniteDifference e Xing são modelos mais sofisticados que levam em consideração os efeitos de cobertura do solo e que possuem muitas semelhanças por terem suas bases fundamentadas nos conceitos desenvolvidos por Xing (2014). No método de simulação FiniteDifference, além de informar as propriedades termofísicas do solo, o usuário deve fornecer dados sobre a umidade do solo e a condição de cobertura do solo ao entorno da edificação. Já o método de simulação Xing exige do usuário informações mais complexas, mas que podem ser facilmente obtidas desde que a localidade da edificação em estudo esteja na tabela de parâmetros desenvolvida em Xing (2014).

\section{Pré-processador Basement (Basement)}

Basement é um programa auxiliar do EnergyPlus. Seu algoritmo de cálculo foi originalmente desenvolvido por Bahnfleth (1989) e Cogil (1998) e modificado posteriormente por Clements (2004) (ANDOLSUN et al., 2011). Seu método numérico é baseado em um modelo tridimensional de diferenças finitas a partir de uma solução numérica alternada implícita, que proporciona uma solução consideravelmente rápida e precisa para um problema complexo como é o cálculo tridimensional da temperatura do solo (CLEMENTS, 2004). Os dados de entrada utilizados no Basement referem-se aos arquivos meteorológicos, às características da edificação e do solo ao entorno da edificação e às condições de operação do próprio programa.

Existem duas formas de executar o Basement (Figura 1). Na primeira delas o Basement é utilizado individualmente por meio de um pré-processador (Basement), em que os resultados gerados pela simulação do ambiente subterrâneo (temperatura da interface parede/laje e solo) são utilizados e inseridos manualmente na simulação do restante da edificação, no EnergyPlus. A segunda opção consiste em um processo de simulação simplificado, dentro da própria simulação da edificação no EnergyPlus (DetailedGroundHeatTransfer:Basement), em que os resultados são fornecidos automaticamente. 
Figura 1 - Formas de acionamento do Basement

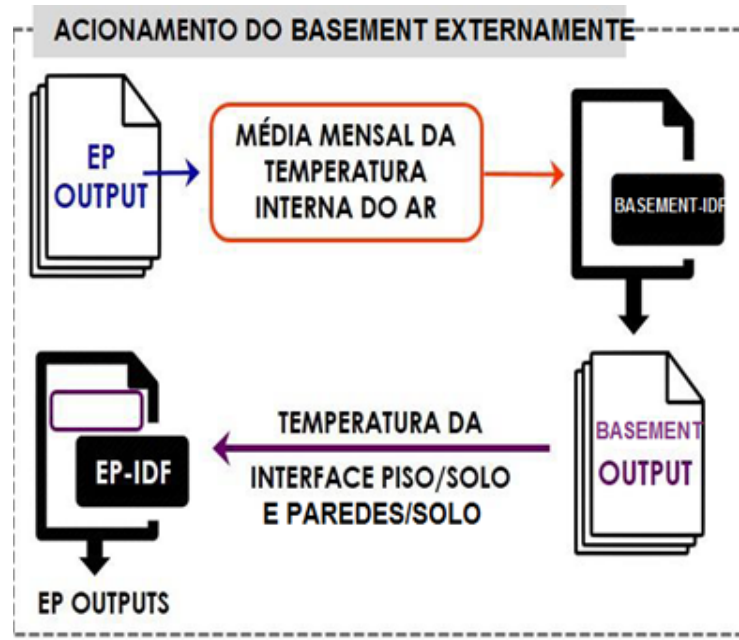

Apesar de mais complexo e de exigir um maior número de dados de entrada, segundo o Auxiliary Programs Manual (DEPARTAMENT..., 2016d), em toda análise no EnergyPlus de superfícies que estão em contato com o solo em que uma maior precisão é requerida é importante especificar apropriadamente as temperaturas do solo. Desse modo, não devem ser utilizadas como temperaturas "não perturbadas" do solo as geradas a partir dos dados meteorológicos fornecidos pelos arquivos climáticos. Ainda, segundo o Auxiliary Programs Manual (DEPARTAMENT..., 2016d), os valores fornecidos pelo objeto GroundDomain são demasiadamente extremos para o solo sob um edifício condicionado. Para obter melhores resultados é importante utilizar o pré-processador Basement. O Auxiliary Programs Manual (DEPARTAMENT..., 2016d) ainda informa que a desconsideração do pré-processador Basement em análises realizadas em edifícios comerciais típicos dos EUA e condicionados artificialmente resulta em redução da temperatura que chega a ser de até $2^{\circ} \mathrm{C}$ abaixo da temperatura média do ar no ambiente interno (DEPARTAMENT..., 2016d).

\section{Método}

Esta seção fornece uma visão geral da metodologia adotada no desenvolvimento deste trabalho que envolve uma abordagem numérica para a avaliação do processo de transferência de calor através do piso e paredes subterrâneos numa residência unifamiliar naturalmente ventilada e não isolada termicamente via EnergyPlus (versão 8.6.0). As alternativas de modelagem utilizadas nas avaliações numéricas são os modelos pertencentes ao objeto GroundDomain (FiniteDifference, KusudaAchenbach e Xing), o pré-processador Basement e o método simplificado GroundTemperature:BuildingSurface.

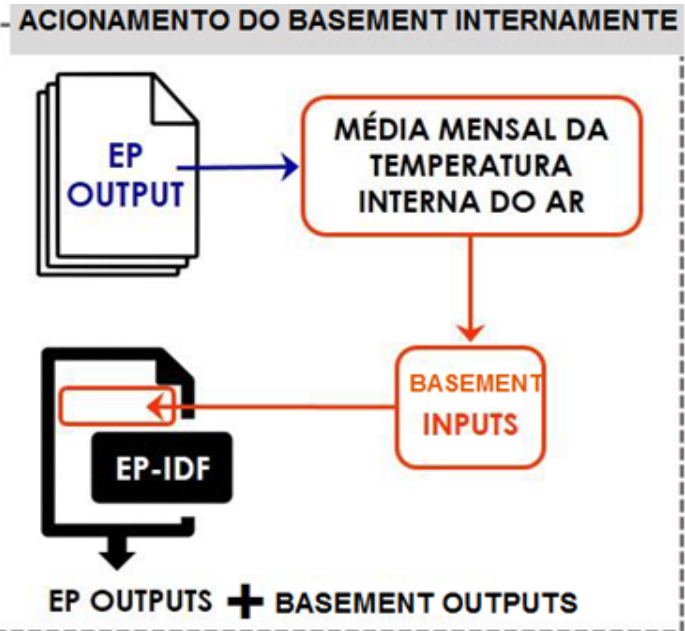

\section{Modelo analisado}

O objeto de estudo deste trabalho é uma edificação unifamiliar de dois pavimentos com $114 \mathrm{~m}^{2}$ de área total. No primeiro pavimento encontra-se um quarto para hóspedes, uma sala de jantar, uma cozinha com acesso externo e um banheiro social, enquanto no subsolo os ambientes são uma sala de estar, dois quartos e outro banheiro social (Figura 2). Segundo recomendações da norma NBR 15575 (ABNT, 2013), deve-se analisar prioritariamente um ambiente de longa permanência para realizar as avaliações de desempenho térmico por simulação computacional. Sendo assim, o ambiente de simulação analisado na pesquisa é um dormitório da Zona 1 (Figura 2), pertencente ao ambiente subterrâneo da edificação.

Ambos os pavimentos possuem $3 \mathrm{~m}$ de pé-direito, tendo o subsolo 2,3 $\mathrm{m}$ de parede sob o solo (Figura 3). A cobertura é de duas águas com beiral de $50 \mathrm{~cm}$ (Figura 4), o que proporciona o sombreamento parcial das aberturas da edificação. Cada ambiente da edificação (quartos, salas, banheiros, corredores e cozinha) representa uma zona térmica de simulação modelada no EnergyPlus, e o vão da escada é modelado como uma única zona térmica com $6 \mathrm{~m}$ de altura. Modelou-se o telhado como duas zonas térmicas de forma que cada água do projeto representa uma zona de simulação dentro do programa. A posição da edificação em estudo está a $0^{\circ}$ do eixo norte de coordenadas geográficas. As janelas são posicionadas conforme indicado na Figura 4 e possuem altura de $1,10 \mathrm{~m}$ no pavimento superior e de $0,50 \mathrm{~m}$ no pavimento subterrâneo. O comprimento das janelas é de 1,0 m nos banheiros e vão da escada e de 2,0 m nos demais cômodos.

O sistema de fechamento interno e externo da edificação possui as características construtivas mencionadas no Quadro 1. Já as propriedades 
termofísicas dos materiais utilizados no sistema de fechamento da edificação são especificadas na Tabela 1. Não há isolamento térmico no piso e nas paredes em contato com o solo, o que é comum para todos os tipos de edificações encontradas na região sudeste brasileira. Em relação à absortância à radiação solar das paredes é assumido o valor de 0,5 , correspondente à cor média definida no projeto, de acordo com a norma NBR 15220-2 (ABNT, 2005a).

Figura 2 - Planta baixa esquemática do objeto de estudo (cotas em metros)
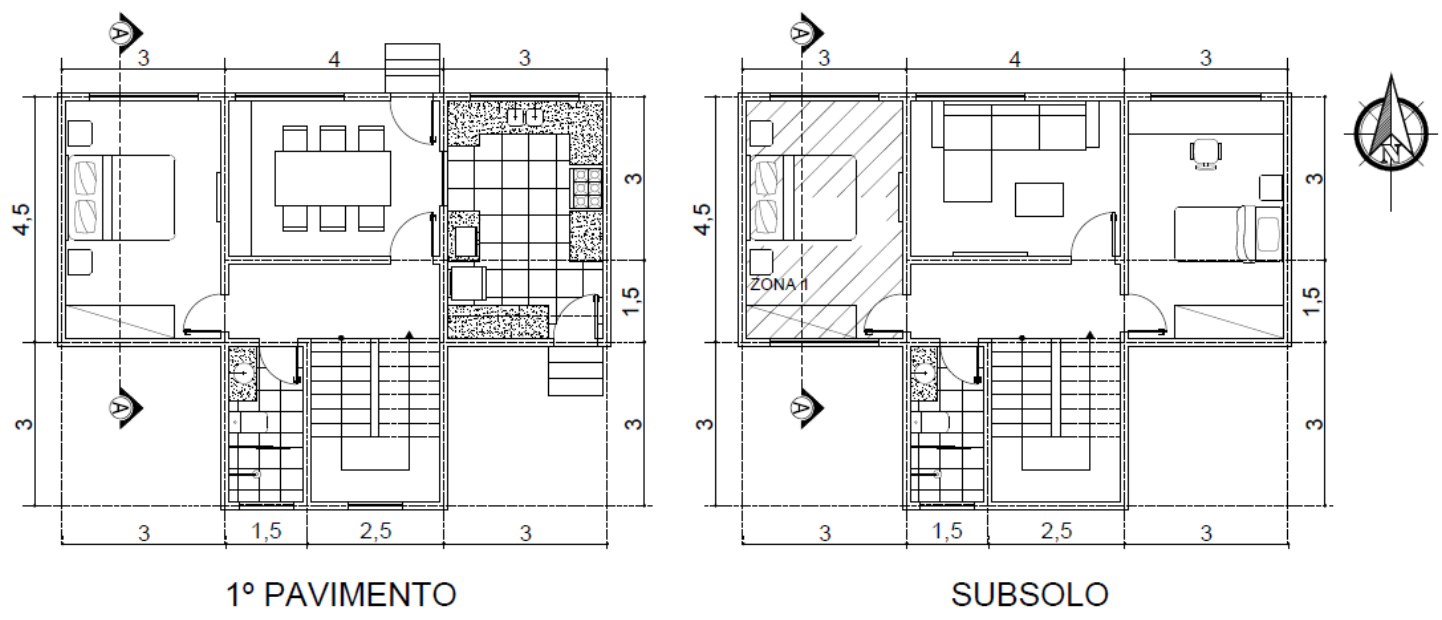

Figura 3 - Corte AA (cotas em m)

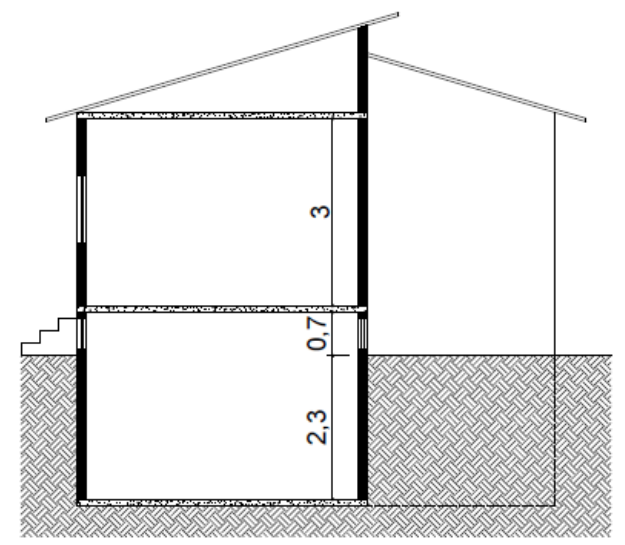

Figura 4 - Perspectivas do modelo
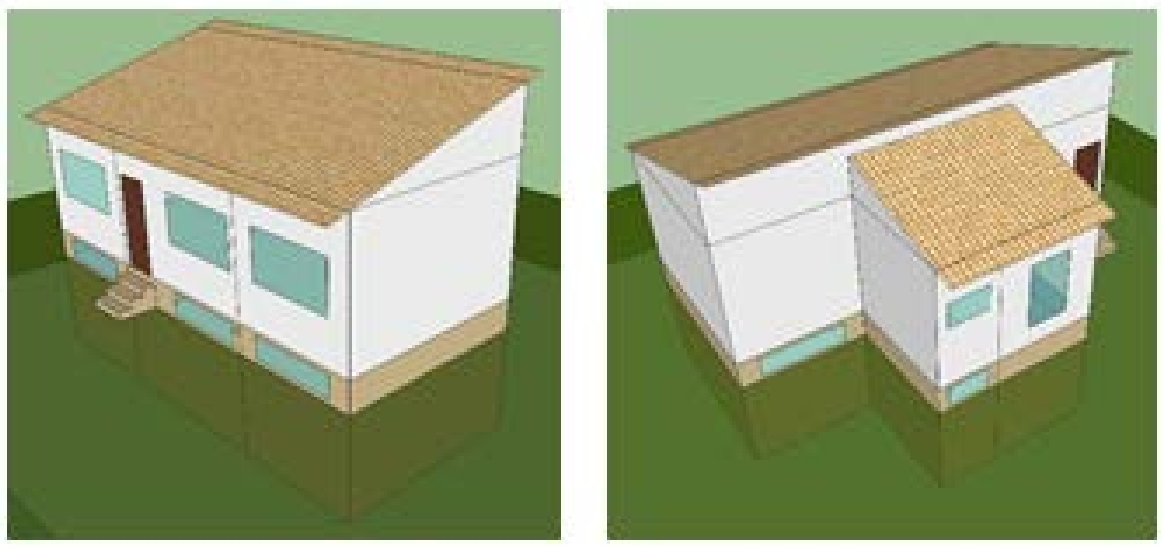
Quadro 1 - Composição dos sistemas fechamento da edificação

\begin{tabular}{|c|c|}
\hline Fechamento & Composição \\
\hline Paredes do porão & Argamassa + Tijolo + Argamassa \\
Paredes do pavimento superior & Laje de concreto + Argamassa + Piso cerâmico \\
Piso do porão & Argamassa + Laje de concreto + Argamassa + Piso cerâmico \\
Piso do pavimento superior & Argamassa + Laje de concreto + Forro de madeira \\
Teto do pavimento superior & Telha cerâmica \\
Telhado & Vidro refletivo de 6 mm de espessura \\
Janelas & Compensado \\
Portas & Grama curta \\
\hline
\end{tabular}

Tabela 1 - Propriedades termofísicas dos materiais utilizados no fechamento da edificação

\begin{tabular}{|c|c|c|c|c|c|c|c|}
\hline \multirow[b]{2}{*}{ Material } & \multirow{2}{*}{$\begin{array}{c}\text { Espessura } \\
\text { (cm) }\end{array}$} & \multicolumn{3}{|c|}{ Propriedades termofísicas ${ }^{1}$} & \multirow[b]{2}{*}{ Fechamento $^{2}$} & \multirow{2}{*}{$\begin{array}{c}U \\
\left(W / \mathbf{m}^{2} K\right)\end{array}$} & \multirow[b]{2}{*}{$C_{T}\left(\mathrm{~kJ} / \mathrm{m}^{2} \mathbf{K}\right)$} \\
\hline & & $\begin{array}{c}k \\
(\mathrm{~W} / \mathrm{mk})\end{array}$ & $\begin{array}{c}\rho \\
\left(\mathbf{k g} / \mathbf{m}^{3}\right)\end{array}$ & $\begin{array}{c}c_{p} \\
(\mathrm{~J} / \mathbf{k g k})\end{array}$ & & & \\
\hline Argamassa & 2,5 & 1,15 & 2.000 & 1.000 & \multirow{2}{*}{ Parede } & \multirow{2}{*}{2,28} & \multirow{2}{*}{168} \\
\hline Tijolo & 10 & 0,9 & 1.600 & 920 & & & \\
\hline Concreto laje & 10 & 1,75 & 2.400 & 1.000 & Laje & 4,40 & 240 \\
\hline Piso cerâmico & 1,5 & 1,05 & 2.000 & 920 & - & 70 & 27,6 \\
\hline Forro de madeira & 1 & 0,2 & 1.400 & 100 & \multirow{2}{*}{ Cobertura } & \multirow{2}{*}{2} & \multirow{2}{*}{32} \\
\hline Telha cerâmica & 1 & 1,05 & 2.000 & 920 & & & \\
\hline Portas de compensado & 3,5 & 0,15 & 550 & 2.300 & - & 4,3 & 44,3 \\
\hline
\end{tabular}

Nota: ${ }^{1}$ propriedades termofísicas dos materiais obtidas de acordo com a norma NBR 15220-2 (ABNT, 2005a), onde $k$ é a condutividade térmica, $\rho$ é a densidade do material e $c_{p}$ é o calor específico do material; e ${ }^{2}$ propriedades termofísicas dos fechamentos obtidas conforme recomendações da norma NBR 15220-3 (ABNT, 2005b), onde $U$ é a transmitância térmica e $C_{T}$ é a capacidade térmica.

\section{Clima}

Para a realização das simulações computacionais, o local escolhido é a cidade de São Paulo, SP, localizada na latitude $23,5^{\circ} \mathrm{S}$ e longitude $46,62^{\circ} \mathrm{W}$, altitude de $792 \mathrm{~m}$ e pertencente à Zona Bioclimática 3, de acordo com a norma brasileira NBR 15220-3 (ABNT, 2005b). O arquivo climático utilizado como referência neste trabalho consta na base de dados climáticos do programa EnergyPlus (UNITED..., 2016). Esse arquivo climático foi desenvolvido por Solar and Wind Energy Resource Assessment (SWERA), no âmbito de um projeto da Organização das Nações Unidas voltado ao meio ambiente. O método utilizado para determinar os dados climáticos desse ano típico (typical meteorological year - TMY) representa condições comumente encontradas no período analisado, sendo desconsideradas condições climáticas atípicas que possam ter ocorrido na série histórica (BRITO, 2015). Ainda segundo Brito (2015), esses dados são adequados para se obterem informações sobre o desempenho térmico de edificações expostas a condições climáticas típicas do local, como abordado neste artigo.

Segundo diretrizes da norma 15575 (ABNT, 2013), a avaliação de desempenho térmico de uma edificação deve ser feita para um dia típico de projeto, de verão e de inverno. Desse modo, informam-se na Tabela 2 os dados climáticos correspondentes aos dias típicos de projeto de verão e de inverno fornecidos pela norma 15575 (ABNT, 2013) para a cidade de São Paulo.

\section{Ventilação natural}

O edifício é considerado naturalmente ventilado pelo uso de janelas, como é comum nas edificações residenciais do local escolhido. A ventilação é modelada utilizando-se o módulo Zone Airflow do EnergyPlus, em que a ventilação para cada zona térmica é testada para uma renovação de ar por hora, conforme recomendações da norma 15575 (ABNT, 2013). Nessas condições, a edificação é analisada considerando-se que a ventilação ocorre apenas por infiltração por meio de frestas em janelas e portas. Como o objetivo deste estudo é comparar os métodos de simulação de ambientes subterrâneos no EnergyPlus, não há necessidade de analisar outros valores de taxas de renovação de ar, pois, apesar de a taxa de ventilação influenciar no desempenho térmico da edificação, essa diferença de desempenho entre os métodos simulados permanece a mesma. 
Tabela 2 - Dados de dias típicos de verão e inverno

\begin{tabular}{c|c|c|c|c|c|c}
\hline \multicolumn{7}{c}{ ZONA BIOCLIMÁTICA 3 (São Paulo, SP) } \\
\hline \multirow{2}{*}{ Estação } & $\begin{array}{c}\text { Te } e^{1} \text { máxima } \\
\text { diária }\left({ }^{\circ} \mathrm{C}\right)\end{array}$ & $\begin{array}{c}\text { Te mínima } \\
\text { diária }\left({ }^{\circ} \mathrm{C}\right)\end{array}$ & $\begin{array}{c}\text { Amplitude diária de } \\
\text { temperatura }\left({ }^{\circ} \mathrm{C}\right)\end{array}$ & $\begin{array}{c}\text { Te bulbo } \\
\text { úmido }\left({ }^{\circ} \mathrm{C}\right)\end{array}$ & $\begin{array}{c}\text { Radiação solar } \\
\left(\mathrm{Wh} / \mathrm{m}^{2}\right)\end{array}$ & $\begin{array}{c}\text { Nebulosidade } \\
(\text { décimos })\end{array}$ \\
\hline Verão & 31,9 & - & 9,2 & 21,3 & 5.180 & 6 \\
Inverno & - & 6,2 & 10 & 13,4 & 4.418 & 6 \\
\hline
\end{tabular}

Nota: ${ }^{1} \mathrm{Te}$ é a temperatura externa do ar.

Tabela 3 - Propriedades termofísicas do solo

\begin{tabular}{l|l|c|c|c}
\hline \multirow{2}{*}{ Material } & \multicolumn{3}{|c}{ Propriedades Termofísicas } \\
\cline { 3 - 5 } \multicolumn{2}{c|}{} & $\begin{array}{c}\text { Densidade } \\
\left(\mathrm{kg} / \mathrm{m}^{3}\right)\end{array}$ & $\begin{array}{c}\text { Calor específico } \\
(\mathrm{J} / \mathrm{kg} . K)\end{array}$ & $\begin{array}{c}\text { Condutividade térmica } \\
(\text { W/m.K) }\end{array}$ \\
\hline \multirow{2}{*}{ Solo Argiloso } & Seco & 1.600 & 890 & 0,25 \\
& Saturado & 2.000 & 1.550 & 1,58 \\
\hline
\end{tabular}

Nota: ${ }^{1}$ as propriedades termofísicas fornecidas por Oke (1995).

\section{Ganhos internos de calor}

A norma NBR 15575 (ABNT, 2013) não considera a presença de fontes internas de calor para que os requisitos mínimos de uma análise de desempenho térmico interno sejam atendidos. Sendo assim, este estudo desconsidera a quantidade de calor gerada pelo perfil de ocupação, que inclui o número de ocupantes e o período de ocupação, o número de equipamentos e o perfil de utilização dos equipamentos, e o nível de iluminação.

\section{Propriedades termofísicas do solo analisado}

Segundo Souza, Amparo e Gomes (2011), o contato da edificação com o solo pode ter um papel importante no balanço térmico da edificação. Devido a sua alta capacidade térmica, o solo é capaz de manter a temperatura do ambiente interno consideravelmente inferior à temperatura do ar ambiente durante o verão e superior à temperatura do ar ambiente durante o inverno (ZAKI; ALMUSAED; KHALIL, 2005). Além disso, em uma mesma região da superfície terrestre podem ser encontrados diversos tipos de solo. Cada tipo possui características próprias, tais como densidade, formato, cor, consistência e formação química, além de variarem seu comportamento de acordo com a presença de água nos vazios no solo (MORSELLI, 2009). Mais especificamente, como o solo argiloso é um dos principais tipos de solo encontrados em São Paulo (BRASIL, 1960), foi o adotado nas simulações. Na Tabela 3 apresentam-se os valores típicos adotados para as principais propriedades termofísicas do solo argiloso, considerando o solo saturado e o solo seco. Em condições de solo saturado, todo o espaço de vazios é ocupado pela água, enquanto para o solo seco todo o espaço de vazios é preenchido por ar. A partir das informações termofísicas do solo, as temperaturas do solo podem ser obtidas com maior exatidão por meio da utilização do pré-processador Basement e do objeto GroundDomain.

Já na análise em que a influência do solo é desconsiderada

(GroundTemperature:BuildingSurface), são apenas utilizadas como valores de referência as temperaturas médias mensais de um solo genérico fornecidas pelo arquivo climático da cidade de São Paulo (Tabela 4).

\section{Dados de entrada e variação das simulações}

As simulações são divididas em três grupos de análises, conforme indicado no Quadro 2. No primeiro grupo realizam-se testes para avaliar o funcionamento do pré-processador Basement mediante as opções de acionamento que o programa apresenta. Já no segundo grupo realizam-se testes para avaliar a operação de todos os procedimentos numéricos encontrados no EnergyPlus para a obtenção da temperatura interna do ambiente subterrâneo. Por fim, no último grupo de análises realizam-se testes com o objetivo de avaliar a influência do tipo de solo nos dados de saída do programa, sendo nestas análises apenas o préprocessador Basement utilizado.

Na Tabela 5 listam-se todos os dados de entrada necessários na simulação do objeto GroundDomain do grupo de simulação 2. Na Tabela 6 listam-se todos os dados de entrada utilizados na simulação do pré-processador Basement, adotado em todos os grupos de simulação. 
Tabela 4 - Temperatura média mensal do solo

\begin{tabular}{c|c|c|c}
\hline Mês & $\begin{array}{c}\text { Temperatura } \\
\text { do solo }\left({ }^{\mathbf{0}} \mathbf{C}\right)^{\mathbf{1}}\end{array}$ & Mês & $\begin{array}{c}\text { Temperatura } \\
\text { do solo }\left({ }^{\mathbf{0}} \mathbf{C}\right)^{\mathbf{1}}\end{array}$ \\
\hline Janeiro & 20,5 & Julho & 17,2 \\
Fevereiro & 21,5 & Agosto & 16,2 \\
Março & 21,7 & Setembro & 15,9 \\
Abril & 21,5 & Outubro & 16,5 \\
Maio & 20,1 & Novembro & 17,6 \\
Junho & 18,6 & Dezembro & 19,1 \\
\hline
\end{tabular}

Nota: ${ }^{1}$ dados obtidos pelo arquivo climático de São Paulo.

\section{Quadro 2 - Grupos de análises e variação das simulações}

\begin{tabular}{|c|c|c|c|}
\hline \multicolumn{2}{|r|}{$\begin{array}{l}\text { Grupos de } \\
\text { Simulação }\end{array}$} & Variações & Observações \\
\hline 1 & $\begin{array}{l}\text { Ativação do } \\
\text { Basement }\end{array}$ & $\begin{array}{l}\text { Basement acionado internamente e Basement } \\
\text { acionado externamente com os mesmos } \\
\text { dados de entrada. }\end{array}$ & $\begin{array}{l}\text { Nas duas situações o pré-processador } \\
\text { Basement é executado uma única vez } \\
\text { e os resultados são comparados. }\end{array}$ \\
\hline 2 & $\begin{array}{c}\text { Variação dos } \\
\text { modelos } \\
\text { encontrados no } \\
\text { EnergyPlus }\end{array}$ & $\begin{array}{l}\text { (a) Fornecendo a temperatura do solo } \\
\text { informada pelo arquivo climático SoilTemp } \\
\text { (b) Utilizando o pré-processador Basement: } \\
\text { Basement } \\
\text { (c) Utilizando o modelo FiniteDifference do } \\
\text { GroundDomain: Gdomain:FD } \\
\text { (d) Utilizando o modelo Kusuda e } \\
\text { Achenbach do GroundDomain: } \\
\text { Gdomain:KA } \\
\text { (e) Utilizando o modelo Xing do } \\
\text { GroundDomain: Gdomain:Xing }\end{array}$ & $\begin{array}{l}\text { Para o caso (a) a temperatura } \\
\text { genérica da Tabela } 4 \text { é inserida no } \\
\text { objeto GroundTemperature do } \\
\text { EnergyPlus. } \\
\text { Para o caso (b) o Basement é } \\
\text { acionado internamente. } \\
\text { Todos os procedimentos adotados } \\
\text { neste grupo são especificados na } \\
\text { seção "Métodos de simulação no } \\
\text { EnergyPlus”. }\end{array}$ \\
\hline 3 & $\begin{array}{l}\text { Influência do } \\
\text { solo }\end{array}$ & $\begin{array}{l}\text { O solo argiloso é testado para duas situações } \\
\text { distintas: seco e saturado. }\end{array}$ & $\begin{array}{l}\text { A Tabela } 3 \text { informa as propriedades } \\
\text { termofísicas do solo analisado. }\end{array}$ \\
\hline
\end{tabular}

Tabela 5 - Dados de entrada para a simulação do objeto GroundDomain (Continua...)

\begin{tabular}{|c|c|c|}
\hline Campos de entrada & Valores adotados & Observações \\
\hline Name & Gdomain & \\
\hline Ground Domain Depth (m) & 15 & $\begin{array}{l}\text { Valor relatado por Shipp, Pfender e Bligh (1981) } \\
\text { como limite inferior onde se estende a influência } \\
\text { térmica no solo. }\end{array}$ \\
\hline Aspect Ratio & 1,63 & $\begin{array}{c}\text { Relação entre altura e largura do ambiente } \\
\text { subterrâneo. }\end{array}$ \\
\hline Perimeter Offset $(\mathrm{m})$ & 5 & \\
\hline $\begin{array}{l}\text { Soil Thermal Condutivity } \\
\text { (W/m.K) }\end{array}$ & 0,25 & \multirow{3}{*}{$\begin{array}{l}\text { Valores estabelecidos na Tabela } 3 \text { para um solo } \\
\text { argiloso seco. }\end{array}$} \\
\hline Soil Density $\left(\mathrm{kg} / \mathrm{m}^{3}\right)$ & 1.600 & \\
\hline Soil Specific Heat (J/kg.K) & 890 & \\
\hline $\begin{array}{l}\text { Soil Moisture Content Volume } \\
\text { Fraction (\%) }\end{array}$ & 30 & \\
\hline $\begin{array}{c}\text { Soil Moisture Content Volume } \\
\text { at Saturation (\%) }\end{array}$ & 50 & \\
\hline $\begin{array}{l}\text { Undisturbed Ground } \\
\text { Temperature Model Type }\end{array}$ & \multicolumn{2}{|c|}{$\begin{array}{l}\text { Site:GroundTemperature:Undisturbed:FiniteDifference (subgrupo (c)), } \\
\text { Site:GroundTemperature:Undisturbed:KusudaAchenbach (subgrupo } \\
\text { (d)) } \\
\text { ou } \\
\text { Site:GroundTemperature:Undisturbed:Xing (subgrupo (e)) }\end{array}$} \\
\hline
\end{tabular}


Tabela 5 - Dados de entrada para a simulação do objeto GroundDomain (continuação)

\begin{tabular}{|c|c|c|}
\hline Campos de entrada & Valores adotados & Observações \\
\hline Undisturbed Ground Temperature Model Type & \multicolumn{2}{|c|}{$\begin{array}{c}\text { Gdomain:FD (subgrupo (c)), Gdomain:KA (subgrupo (d)), } \\
\text { Gdomain:Xing (subgrupo (e)) }\end{array}$} \\
\hline Evapotranspiration Ground Cover Parameter & 1 & $\begin{array}{l}\text { Valor recomendado para } \\
\text { grama curta. }\end{array}$ \\
\hline Basement Floor Boundary Condition Model Name & BasementFloorOSCM & \\
\hline Horizontal Insulation & No & \multirow{4}{*}{$\begin{array}{l}\text { Não existe isolamento } \\
\text { horizontal (laje em contato } \\
\text { com o solo). }\end{array}$} \\
\hline Horizontal Insulation Material Name & & \\
\hline Horizontal Insulation Extends & & \\
\hline Perimeter Horizontal Insulation Width $(\mathrm{m})$ & 0,1 & \\
\hline Basement Wall Boundary Condition Model Name & BasementWallOSCM & \\
\hline Vertical Insulation & No & \multirow{3}{*}{$\begin{array}{c}\text { Não existe isolamento vertical } \\
\text { (paredes em contato com o } \\
\text { solo). }\end{array}$} \\
\hline Vertical Insulation Material Name & & \\
\hline Vertical Insulation Depth $(\mathrm{m})$ & 2,3 & \\
\hline Simulation Timestep & timestep & \\
\hline Mesh Density Parameter & 4 & \\
\hline \multicolumn{3}{|c|}{ Dados de entrada do GroundTemperature:Shallow } \\
\hline Campos de entrada & Valores adotados & Observações \\
\hline January - December Surface Ground Temperature & \multicolumn{2}{|c|}{$\begin{array}{l}\text { Valores mensais de temperatura externa do ar fornecidos } \\
\text { pelo arquivo climático de São Paulo. }\end{array}$} \\
\hline \multicolumn{3}{|c|}{ Site:GroundTemperature:Undisturbed:FiniteDifference (subgrupo (c)) } \\
\hline Campos de entrada & Valores adotados & Observações \\
\hline Name & Gdomain:FD & \\
\hline Soil Thermal Condutivity (W/m.K) & 0,25 & \multirow{3}{*}{$\begin{array}{c}\text { Valores estabelecidos na } \\
\text { Tabela } 3 \text { para um solo argiloso } \\
\text { seco. }\end{array}$} \\
\hline Soil Density $\left(\mathrm{kg} / \mathrm{m}^{3}\right)$ & 1.600 & \\
\hline Soil Specific Heat (J/kg.K) & 890 & \\
\hline Soil Moisture Content Volume Fraction (\%) & 30 & \\
\hline Soil Moisture Content Volume at Saturation (\%) & 50 & \\
\hline Evapotranspiration Ground Cover Parameter & 1 & $\begin{array}{l}\text { Valor recomendado para } \\
\text { grama curta. }\end{array}$ \\
\hline \multicolumn{3}{|c|}{ Site:GroundTemperature:Undisturbed:KusudaAchenbach (subgrupo (d)) } \\
\hline Campos de entrada & Valores adotados & Observações \\
\hline Name & Gdomain:KA & \\
\hline Soil Thermal Condutivity (W/m.K) & 0,25 & \multirow{3}{*}{$\begin{array}{c}\text { Valores estabelecidos na } \\
\text { Tabela } 3 \text { para um solo argiloso } \\
\text { seco. }\end{array}$} \\
\hline Soil Density $\left(\mathrm{kg} / \mathrm{m}^{3}\right)$ & 1.600 & \\
\hline Soil Specific Heat (J/kg.K) & 890 & \\
\hline Average Soil Surface Temperature (C) & & \multirow{3}{*}{$\begin{array}{l}\text { Valores omitidos por falta de } \\
\text { dados. Neste caso, o programa } \\
\text { utiliza os dados fornecidos no } \\
\text { objeto } \\
\text { GroundTemperature:Shallow } \\
\text { para calcular os parâmetros. }\end{array}$} \\
\hline Average Amplitude of Surface Temperature $(\Delta C)$ & & \\
\hline Phase Shift of Minimum Surface Temperature (dia) & & \\
\hline \multicolumn{3}{|c|}{ Site:GroundTemperature:Undisturbed:Xing (subgrupo (e)) } \\
\hline Campos de entrada & Valores adotados & Observações \\
\hline Name & Gdomain:Xing & \\
\hline Soil Thermal Condutivity (W/m.K) & 0,25 & \multirow{3}{*}{$\begin{array}{c}\text { Valores estabelecidos na } \\
\text { Tabela } 3 \text { para um solo argiloso } \\
\text { seco. }\end{array}$} \\
\hline Soil Density $\left(\mathrm{kg} / \mathrm{m}^{3}\right)$ & 1.600 & \\
\hline Soil Specific Heat (J/kg.K) & 890 & \\
\hline Average Soil Surface Temperature (C) & 21,1 & \multirow{5}{*}{$\begin{array}{c}\text { Valores definidos por Xing } \\
\text { (2014) para a cidade de São } \\
\text { Paulo. }\end{array}$} \\
\hline Soil Surface Temperature Amplitude $1(\Delta C)$ & $-3,3$ & \\
\hline Soil Surface Temperature Amplitude $2(\Delta C)$ & 0,8 & \\
\hline Phase Shift of Temperature Amplitude 1 (dia) & 19 & \\
\hline Phase Shift of Temperature Amplitude 2 (dia) & -8 & \\
\hline \multicolumn{3}{|c|}{ SurfaceProperty:OtherSideConditionsModel } \\
\hline Campos de entrada & Valores adotados & Valores adotados \\
\hline Name & BasementWallOSCM & BasementFloorOSCM \\
\hline Type of Modeling & $\begin{array}{l}\text { UndergroundPiping } \\
\text { SystemSurface }\end{array}$ & $\begin{array}{l}\text { UndergroundPiping } \\
\text { SystemSurface. }\end{array}$ \\
\hline
\end{tabular}


Tabela 6 - Dados de entrada para a simulação do pré-processador Basement (Continua...)

\begin{tabular}{|c|c|c|}
\hline \multicolumn{3}{|c|}{ GroundHeatTransfer:Control } \\
\hline Campos de entrada & Valores adotados & Observações \\
\hline Name & Basement & \\
\hline Run Basement Preprocessor & Yes & \multirow{2}{*}{$\begin{array}{c}\text { Opção do tipo de pré-processador para determinar a } \\
\text { temperatura do solo que é utilizado: Slab (simulação } \\
\text { de lajes) e Basement (simulação de ambientes } \\
\text { subterrâneos). }\end{array}$} \\
\hline Run Slab Preprocessor & No & \\
\hline \multicolumn{3}{|c|}{ GroundHeatTransfer:Basement:SimParameters } \\
\hline Campos de entrada & Valores adotados & Observações \\
\hline F: Multiplier for the ADI Solution & 0,1 & Valor recomendado por Clements (2004). \\
\hline IYRS: Maximum number of yearly iterations & 15 & $\begin{array}{l}\text { Número máximo de anos para encerrar a simulação } \\
\text { caso não haja a convergência. }\end{array}$ \\
\hline \multicolumn{3}{|c|}{ GroundHeatTransfer:Basement:MatProps } \\
\hline Campos de entrada & Valores adotados & Observações \\
\hline NMAT: Number of material in this domain & 6 & $\begin{array}{l}\text { Campo que especifica o número de materiais } \\
\text { presentes no ambiente subterrâneo cujas } \\
\text { propriedades são especificadas. }\end{array}$ \\
\hline Density for Foundation Wall $\left(\mathrm{kg} / \mathrm{m}^{3}\right)$ & 1.600 & \multirow{9}{*}{$\begin{array}{l}\text { Propriedades termofísicas dos materiais presentes no } \\
\text { ambiente subterrâneo (paredes, laje em contato com } \\
\text { o solo, teto do pavimento subterrâneo, as } \\
\text { propriedades do cascalho utilizados como dreno } \\
\text { entre as paredes e o solo e a madeira utilizada) e do } \\
\text { solo. As propriedades dos materiais são as mesmas } \\
\text { presentes na Tabela } 1 \text {. As propriedades da madeira e } \\
\text { do cascalho são os valores de referência fornecidos } \\
\text { pelo EnergyPlus. }\end{array}$} \\
\hline Density for Floor Slab $\left(\mathrm{kg} / \mathrm{m}^{3}\right)$ & 2.400 & \\
\hline Density for Ceiling $\left(\mathrm{kg} / \mathrm{m}^{3}\right)$ & 2.400 & \\
\hline Density for Soil $\left(\mathrm{kg} / \mathrm{m}^{3}\right)$ & 1.600 & \\
\hline Density for Gravel $\left(\mathrm{kg} / \mathrm{m}^{3}\right)$ & 2.000 & \\
\hline Density for Wood $\left(\mathrm{kg} / \mathrm{m}^{3}\right)$ & 449 & \\
\hline Specific heat for Foundation Wall (J/kg.K) & 920 & \\
\hline Specifc heat for Floor Slab (J/kg.K) & 1.000 & \\
\hline Specific heat for Ceiling (J/kg.K) & 1.000 & \\
\hline Campos de entrada & Valores adotados & Observações \\
\hline Specific heat for Soil (J/kg.K) & 890 & \multirow{9}{*}{$\begin{array}{c}\text { Propriedades termofísicas dos materiais presentes no } \\
\text { ambiente subterrâneo (paredes, laje em contato com } \\
\text { o solo, teto do pavimento subterrâneo, as } \\
\text { propriedades do cascalho utilizados como dreno } \\
\text { entre as paredes e o solo e a madeira utilizada) e do } \\
\text { solo. As propriedades dos materiais são as mesmas } \\
\text { presentes na Tabela 1. As propriedades da madeira e } \\
\text { do cascalho são os valores de referência fornecidos } \\
\text { pelo EnergyPlus. }\end{array}$} \\
\hline Specific heat for Gravel (J/kg.K) & 720 & \\
\hline Specific heat for Wood (J/kg.K) & 1.530 & \\
\hline $\begin{array}{l}\text { Thermal conductivity for Foundation Wall } \\
\qquad(W / m . K)\end{array}$ & 0,9 & \\
\hline $\begin{array}{l}\text { Thermal conductivity for Floor Slab } \\
(W / m . K)\end{array}$ & 1,75 & \\
\hline Thermal conductivity for Ceiling (W/m.K) & 1,75 & \\
\hline Thermal conductivity for soil (W/m.K) & 0,25 & \\
\hline Thermal conductivity for Gravel (W/m.K) & 1,9 & \\
\hline Thermal conductivity for Wood (W/m.K) & 0,12 & \\
\hline \multicolumn{3}{|c|}{ GroundHeatTransfer:Basement:Insulation } \\
\hline Campos de entrada & Valores adotados & Observações \\
\hline $\begin{array}{c}\text { REXT: } R \text { Value of any exterior insulation } \\
\left(\mathrm{m}^{2} . \mathrm{K} / \mathrm{W}\right)\end{array}$ & 0,000001 & \multirow{2}{*}{$\begin{array}{l}\text { Um valor de resistência térmica do material de } \\
\text { isolamento próximo a zero é adotado para } \\
\text { representar a situação simulada neste trabalho. }\end{array}$} \\
\hline INSFULL: Flag: Is the wall fully insulated? & TRUE & \\
\hline \multicolumn{3}{|c|}{ GroundHeatTransfer:Basement:SurfaceProps } \\
\hline Campos de entrada & Valores adotados & Ições \\
\hline $\begin{array}{c}\text { ALBEDO: Surface albedo for No snow } \\
\text { conditions }\end{array}$ & 0,26 & \multirow{6}{*}{$\begin{array}{c}\text { Os valores adotados para a condição de solo com } \\
\text { grama curta e coberto por neve são fornecidos em } \\
\text { Oke (1995) para o albedo, a emissividade e a } \\
\text { rugosidade da superfície. }\end{array}$} \\
\hline $\begin{array}{l}\text { ALBEDO: Surface albedo for snow } \\
\text { conditions }\end{array}$ & 0,4 & \\
\hline EPSLN: Surface emissivity No snow & 0,95 & \\
\hline EPSLN: Surface emissivity snow & 0,99 & \\
\hline $\begin{array}{c}\text { VEGHT: Surface roughness No snow } \\
\text { conditions }(\mathrm{cm})\end{array}$ & 0,1 & \\
\hline $\begin{array}{l}\text { VEGHT: Surface roughness snow } \\
\text { conditions }(\mathrm{cm})\end{array}$ & 0,1 & \\
\hline $\begin{array}{c}\text { PET: Flag, Potential evapotranspiration } \\
\text { on? }\end{array}$ & TRUE & $\begin{array}{l}\text { Sub-rotina responsável por calcular a } \\
\text { evapotranspiração na superfície do solo. }\end{array}$ \\
\hline
\end{tabular}


Tabela 6 - Dados de entrada para a simulação do pré-processador Basement (continuação)

\begin{tabular}{|c|c|c|}
\hline \multicolumn{3}{|c|}{ GroundHeatTransfer:Basement:BldgData } \\
\hline Campos de entrada & Valores adotados & Observações \\
\hline DWALL: Wall thickness (m) & 0,2 & \multirow{2}{*}{$\begin{array}{l}\text { Espessura da parede e laje do cômodo subterrâneo, } \\
\text { conforme apresentado nas Tabelas } 1 \text { e } 2 \text {. }\end{array}$} \\
\hline DSLAB: Floor slab tickness $(\mathrm{m})$ & 0,1 & \\
\hline $\begin{array}{c}\text { DGRAVXY: Width of gravel pit beside } \\
\text { basement wall }(\mathrm{m})\end{array}$ & 0,3 & $\begin{array}{l}\text { Espessura de cascalho adotado como material } \\
\text { responsável pela drenagem de água ao redor das } \\
\text { paredes e da laje do cômodo subterrâneo. Os valores } \\
\text { adotados são os valores de referência do EnergyPlus. }\end{array}$ \\
\hline Campos de entrada & Valores adotados & Observações \\
\hline $\begin{array}{c}\text { DGRAVZN: Gravel depth extending above } \\
\text { the floor slab }(\mathrm{m})\end{array}$ & 0,3 & \multirow{2}{*}{$\begin{array}{l}\text { Espessura de cascalho adotado como material } \\
\text { responsável pela drenagem de água ao redor das } \\
\text { paredes e da laje do cômodo subterrâneo. Os valores } \\
\text { adotados são os valores de referência do EnergyPlus. }\end{array}$} \\
\hline DGRAVZP: Gravel depth below floor slab (m) & 0,1 & \\
\hline \multicolumn{3}{|c|}{ GroundHeatTransfer:Basement:Interior } \\
\hline Campos de entrada & Valores adotados & Observações \\
\hline COND: Flag: Is the basement conditioned? & FALSE & $\begin{array}{l}\text { Sub-rotina que informa que o ambiente subterrâneo } \\
\text { não é condicionado artificialmente. }\end{array}$ \\
\hline $\begin{array}{l}\text { HIN: Downward convection only heat } \\
\text { transfer coefficient }\left(\mathrm{W} / \mathrm{m}^{2} . K\right)\end{array}$ & 0,92 & \multirow{6}{*}{$\begin{array}{c}\text { Os valores adotados são os valores de referência do } \\
\text { EnergyPlus. }\end{array}$} \\
\hline $\begin{array}{c}\text { HIN: Upward convection only heat transfer } \\
\text { coefficient }\left(\mathrm{W} / \mathrm{m}^{2} . \mathrm{K}\right)\end{array}$ & 4,04 & \\
\hline $\begin{array}{l}\text { HIN: Horizontal convection only heat } \\
\text { transfer coefficient }\left(\mathrm{W} / \mathrm{m}^{2} . \mathrm{K}\right)\end{array}$ & 3,08 & \\
\hline $\begin{array}{c}\text { HIN: Downward combined (convection and } \\
\text { radiation) heat transfer coefficient } \\
\left(\mathrm{W} / \mathrm{m}^{2} . \mathrm{K}\right)\end{array}$ & 6,13 & \\
\hline $\begin{array}{l}\text { HIN: Upward combined (convection and } \\
\text { radiation) heat transfer coefficient } \\
\qquad\left(\mathrm{W} / \mathrm{m}^{2} . \mathrm{K}\right)\end{array}$ & 9,26 & \\
\hline $\begin{array}{c}\text { HIN: Horizontal combined (convection and } \\
\text { radiation) heat transfer coefficient } \\
\left(\mathrm{W} / \mathrm{m}^{2} . \mathrm{K}\right)\end{array}$ & 8,29 & \\
\hline \multicolumn{3}{|c|}{ GroundHeatTransfer:Basement:ComBldg 1} \\
\hline Campos de entrada & Valores adotados & ações \\
\hline January average temperature $(C)$ & 17,3 & \multirow{12}{*}{$\begin{array}{l}\text { Valores informados para a temperatura interna mensal } \\
\text { do ambiente subterrâneo ao longo de um ano. Neste } \\
\left.\text { trabalho, o valor de referência do EnergyPlus ( } 22^{\circ} \mathrm{C}\right) \text { é } \\
\text { adotado na simulação preliminar. Os dados de saída } \\
\text { (temperatura interna do ambiente subterrâneo) } \\
\text { fornecidos pela simulação preliminar são utilizados } \\
\text { para obter a média ponderada levando-se em conta as } \\
\text { temperaturas obtidas para cada zona de simulação e sua } \\
\text { respectiva área (divisão da temperatura obtida para cada } \\
\text { zona térmica x área de cada zona pela área total do } \\
\text { ambiente subterrâneo). Os valores obtidos são então } \\
\text { inseridos na simulação principal do modelo. }\end{array}$} \\
\hline February average temperature $(C)$ & 23,7 & \\
\hline March average temperature $(C)$ & 23,6 & \\
\hline April average temperature $(C)$ & 22,5 & \\
\hline May average temperature (C) & 21,0 & \\
\hline June average temperature $(C)$ & 19,6 & \\
\hline July average temperature (C) & 19,2 & \\
\hline August average temperature (C) & 19,8 & \\
\hline September average temperature $(C)$ & 20,3 & \\
\hline October average temperature $(C)$ & 20,7 & \\
\hline November average temperature $(C)$ & 21,6 & \\
\hline December average temperature $(C)$ & 22,7 & \\
\hline Daily variation sine wave amplitude $(\Delta C)$ & & \\
\hline \multicolumn{3}{|c|}{ GroundHeatTransfer:Basement:EquivSlab } \\
\hline Campos de entrada & Valores adotados & Observações \\
\hline $\begin{array}{l}\text { APRatio: The area to perimeter ratio for } \\
\text { this slab }(\mathrm{m})\end{array}$ & 1,63 & $\begin{array}{l}\text { Relação entre a área e o perímetro do ambiente } \\
\text { subterrâneo. }\end{array}$ \\
\hline EquivSizing: Flag & TRUE & \\
\hline \multicolumn{3}{|c|}{ GroundHeatTransfer:Basement:EquivAutoGrid } \\
\hline Campos de entrada & Valores adotados & Observações \\
\hline $\begin{array}{l}\text { CLEARANCE: Distance from outside of } \\
\text { wall to edge of } 3-D \text { ground domain }(\mathrm{m})\end{array}$ & 12 & $\begin{array}{l}\text { Valor estabelecido por Shipp, Pfender e Bligh (1981) } \\
\text { para definir a faixa de solo (distância) ao redor da } \\
\text { edificação que deve ser considerada nas simulações. }\end{array}$ \\
\hline SlabDepth: Thickness of the floor slab $(\mathrm{m})$ & 0,1 & \multirow[b]{2}{*}{ Dados referentes à geometria da edificação. } \\
\hline $\begin{array}{c}\text { BaseDepth: Depth of the basement wall } \\
\text { below grade }(\mathrm{m})\end{array}$ & 2,3 & \\
\hline
\end{tabular}

Nota: ${ }^{1}$ requer uma simulação preliminar para determinar a temperatura interna para os 12 meses do ano. Os valores obtidos pela simulação preliminar são então adotados para executar a simulação principal da edificação analisada. 
Os dados de saída utilizados foram a temperatura do ar externa e a temperatura interna (horária) de cada zona da edificação, gerados pelo EnergyPlus, e as temperaturas das paredes e piso do cômodo subterrâneo, gerados pelo pré-processador Basement. A operação de todos os modelos numéricos e o impacto que as possibilidades de modelagem analisadas nas simulações exercem sobre a temperatura interna do ambiente subterrâneo são examinados no grupo de simulação 2. Este estudo ainda investiga como a escolha sobre o tipo de método de simulação influencia na avaliação de desempenho térmico da edificação. Para tal, adota como limites de desempenho térmico os critérios estabelecidos pela norma 15575 (ABNT, 2013), analisando-se um dia típico de projeto de verão e um dia típico de projeto de inverno, conforme se apresenta na Tabela 7.

\section{Resultados e discussão}

Apresenta-se a comparação dos resultados obtidos para as simulações presentes no Quadro 2 da metodologia. Os resultados são divididos em três seções:

(a) ativação interna e externa do pré-processador Basement no EnergyPlus (grupo de simulação 1); (b) comparação de todos os métodos de simulação presentes no EnergyPlus - GroundDomain (FiniteDifference, KusudaAchenbach, Xing), Basement - e a situação em que não se utiliza nenhum método para a obtenção da temperatura do solo (grupo de simulação 2); e

(c) influência das propriedades termofísicas do solo (grupo de simulação 3).

\section{Resultados obtidos para o grupo de simulação 1}

Esta etapa dos resultados avaliou a operação do préprocessador Basement mediante as duas formas de acionamento presentes no programa: acionamento interno e externo. As simulações foram realizadas utilizando-se os dois tipos de ativação, conforme as recomendações descritas na seção "Métodos de Simulação no EnergyPlus” e os mesmos dados de entrada presentes na Tabela 6. Sendo assim, apresentam-se na Tabela 8 os resultados gerados pelo pré-processador Basement para a temperatura externa das paredes e piso do ambiente subterrâneo e para as duas formas de acionamento do programa. Ambas as simulações apresentaram todas as variáveis de saída com valores idênticos. Isso indica que, quando Basement é ativado internamente, ele funciona corretamente.

Tabela 7 - Critério de avaliação de desempenho térmico

Fonte: ABNT, 2013.

\begin{tabular}{c|c|c}
\hline Nível de Desempenho & Verão & Inverno \\
\hline Mínimo & $\mathrm{T}_{\mathrm{i}, \max } \leq \mathrm{T}_{\mathrm{e}, \max }$ & $\mathrm{T}_{\mathrm{i}, \min } \geq\left(\mathrm{T}_{\mathrm{e}, \min }+3{ }^{\circ} \mathrm{C}\right)$ \\
Intermediário & $\mathrm{T}_{\mathrm{i}, \max } \leq\left(\mathrm{T}_{\mathrm{e}, \max }-2^{\circ} \mathrm{C}\right)$ & $\mathrm{T}_{\mathrm{i}, \min } \geq\left(\mathrm{T}_{\mathrm{e}, \min }+5^{\circ} \mathrm{C}\right)$ \\
Superior & $\mathrm{T}_{\mathrm{i}, \max } \leq\left(\mathrm{T}_{\mathrm{e}, \max }-4{ }^{\circ} \mathrm{C}\right)$ & $\mathrm{T}_{\mathrm{i}, \min } \geq\left(\mathrm{T}_{\mathrm{e}, \min }+7^{\circ} \mathrm{C}\right)$ \\
\hline
\end{tabular}

Ti, max é o valor máximo diário da temperatura do ar no interior da edificação (ㅇ C);

Te, max é o valor máximo diário da temperatura do ar exterior à edificação (o $\mathrm{C}$ );

Ti, min é o valor mínimo diário da temperatura do ar no interior da edificação (ㅇ C); e

Te, miné o valor mínimo diário da temperatura do ar exterior à edificação (o C).

Tabela 8 - Temperatura da face externa das paredes e piso do ambiente subterrâneo

\begin{tabular}{c|c|c|c|c|c|c}
\hline \multicolumn{6}{c}{ Temperatura da face externa das paredes e piso em contato com o solo $\left({ }^{\circ} \mathbf{C}\right)$} \\
\hline \multirow{2}{*}{ Mês } & \multicolumn{2}{|c|}{ Acionamento interno } & Acionamento externo & \multicolumn{2}{|c}{ Diferença $(\%)$} \\
\cline { 2 - 7 } & Parede & Piso & Parede & Piso & Parede & Piso \\
\hline Janeiro & 14,6 & 13,4 & 14,6 & 13,4 & 0 & 0 \\
Fevereiro & 17,9 & 17,6 & 17,9 & 17,6 & 0 & 0 \\
Março & 18,2 & 17,8 & 18,2 & 17,8 & 0 & 0 \\
Abril & 17,6 & 17,1 & 17,6 & 17,1 & 0 & 0 \\
Maio & 16,4 & 16,0 & 16,4 & 16,0 & 0 & 0 \\
Junho & 15,4 & 15,0 & 15,4 & 15,0 & 0 & 0 \\
Julho & 15,0 & 14,7 & 15,0 & 14,7 & 0 & 0 \\
Agosto & 15,4 & 15,1 & 15,4 & 15,1 & 0 & 0 \\
Setembro & 15,8 & 15,4 & 15,8 & 15,4 & 0 & 0 \\
Outubro & 16,0 & 15,7 & 16,0 & 15,7 & 0 & 0 \\
Novembro & 16,7 & 16,3 & 16,7 & 16,3 & 0 & 0 \\
Dezembro & 17,6 & 17,2 & 17,6 & 17,2 & 0 & 0 \\
\hline
\end{tabular}




\section{Resultados obtidos para o grupo de simulação 2}

Apresentam-se nas Figuras 5 e 6 os resultados da temperatura interna e externa para um dia típico de verão e um de inverno e para os diferentes tipos de modelos disponíveis no programa capazes de analisar o processo de troca de calor de ambientes em contato com o solo.

Figura 5 - Evolução temporal da temperatura interna e externa do ar para um dia típico de verão

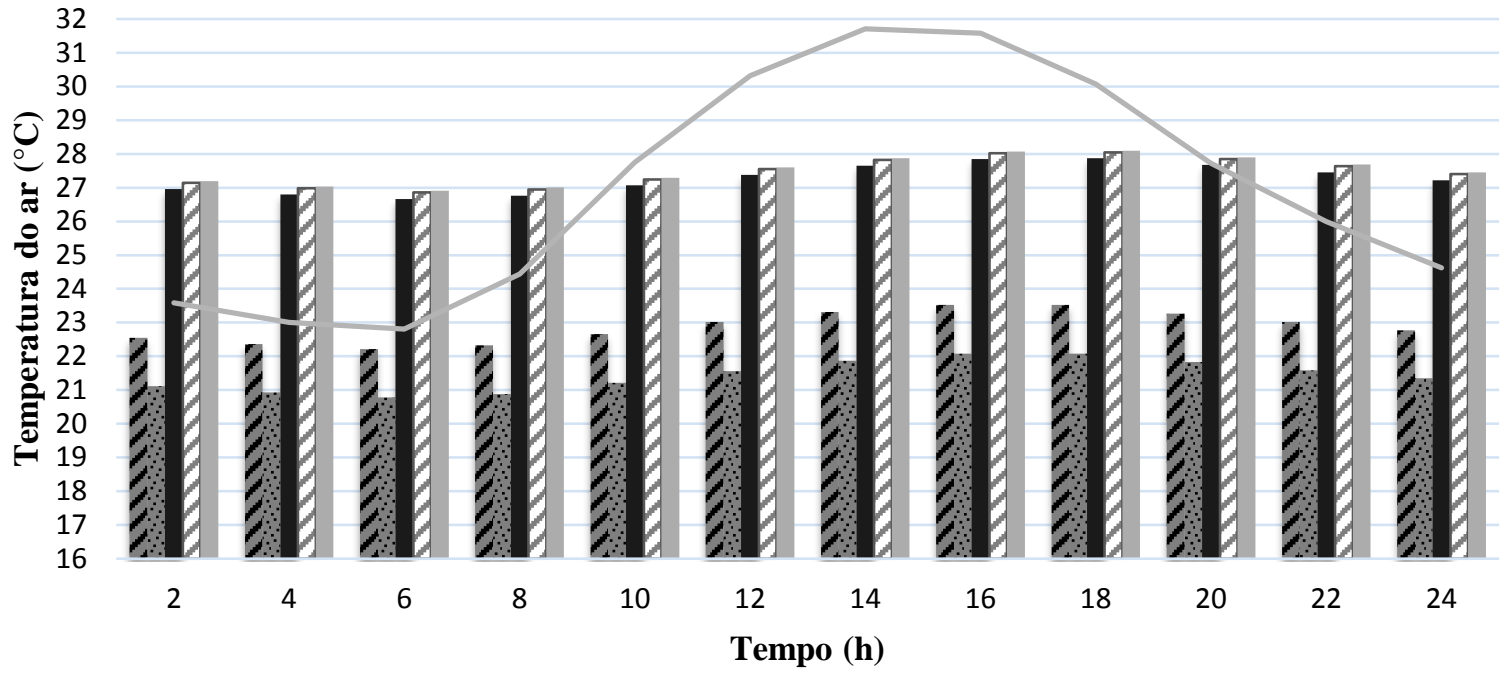

$\varkappa$ SoilTemp

$\lessdot$ Gdomain:KA
5 Basement

Gdomain:Xing
Gdomain:FD

Temperatura Externa $\left({ }^{\circ} \mathrm{C}\right)$

Figura 6 - Evolução temporal da temperatura interna e externa do ar para um dia típico de inverno

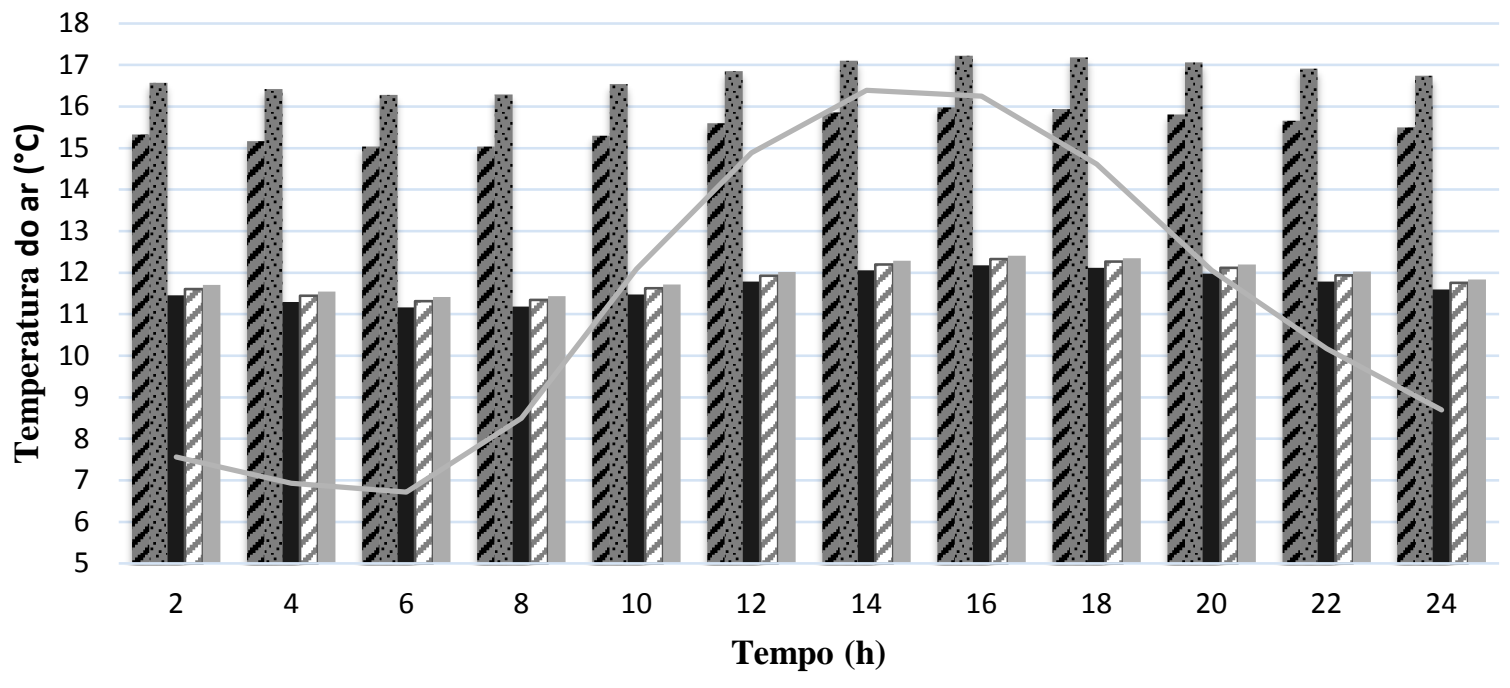

$\angle$ SoilTemp

$\not{Z}$ Gdomain:KA

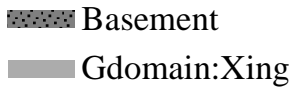

Gdomain:FD

— Temperatura Externa $\left({ }^{\circ} \mathrm{C}\right)$ 
No verão as menores temperaturas são obtidas na análise em que o pré-processador Basement é considerado, enquanto as temperaturas mais elevadas são encontradas para a análise do GroundDomain. Nota-se que o critério de desempenho mínimo estabelecido pela norma NBR 15575 (ABNT, 2013) é atendido para todas as alternativas de modelagem, em que o valor máximo diário da temperatura do ar interior é menor que o valor máximo diário da temperatura do ar exterior $\left(31,9{ }^{\circ} \mathrm{C}\right)$. Assim como ocorre no verão, o critério de desempenho mínimo estabelecido pela mesma norma para o inverno também é atendido para todos os tipos diferentes de modelagem, em que os valores mínimos diários da temperatura do ar interior $\left(6,7^{\circ} \mathrm{C}\right)$ são maiores que a temperatura mínima externa acrescida de $3{ }^{\circ} \mathrm{C}$. Já em relação ao nível de desempenho intermediário, todos os modelos alcançam essa classificação no período de verão, mas ela não é atingida nos modelos pertencentes ao GroundDomain. Quanto ao nível de desempenho superior estabelecido pela norma, apenas os modelos Basement e SoilTemp atingem o desempenho superior no verão e no inverno.

A Tabela 9 mostra os valores máximos obtidos para a temperatura interna do ar do ambiente subterrâneo para um dia típico de verão e os valores mínimos obtidos para as simulações de um dia típico de inverno para todos os modelos analisados. Os dados indicam que entre os modelos pertencentes ao objeto GroundDomain os resultados são muito próximos, alcançando uma variação máxima de apenas $0,3{ }^{\circ} \mathrm{C}$ entre os modelos FiniteDifference e KusudaAchenbach no verão e de $0,2{ }^{\circ} \mathrm{C}$ entre os modelos

FiniteDifference
KusudaAchenbach/Xing no verão. Comparando os resultados do pré-processador Basement com os resultados do GroundDomain, essa variação tornase mais acentuada, chegando a alcançar até $6{ }^{\circ} \mathrm{C}$ (27\%) de diferença no verão e $5,2{ }^{\circ} \mathrm{C}$ (32\%) no inverno. Por fim, comparando-se os resultados gerados pelo Basement e os dados provenientes da simulação em que a influência do solo não é considerada (SoilTemp), a variação de temperatura atinge um valor máximo de $1,5^{\circ} \mathrm{C}(6,7 \%)$ no verão e de $1,3{ }^{\circ} \mathrm{C}$ (8\%) no inverno. Já em relação ao GroundDomain, essa diferença chega a ser de 4,5 ${ }^{\circ} \mathrm{C}$ (16\%) no verão e de $3,9{ }^{\circ} \mathrm{C}$ (35\%) no inverno. Em relação às temperaturas nas interfaces solo/piso e solo/paredes, é possível notar que a temperatura das interfaces em contato com o solo é geralmente mais baixa que a temperatura interna do ar no ambiente subterrâneo no verão. Sendo assim, há tendência de o cômodo subterrâneo sempre fornecer calor para o solo com a finalidade de encontrar o equilíbrio térmico. Fato oposto ocorre para a análise de um dia típico de inverno, quando as paredes e piso que estão em contato com o solo tendem a conduzir calor para o interior do ambiente.

Tomando-se como referência os dados de saída gerados pela simulação do Basement, obteve-se o gráfico mostrado na Figura 7, que indica a variação máxima de temperatura do ar existente no verão e no inverno entre o pré-processador Basement e os demais modelos testados. Nota-se que no verão as temperaturas fornecidas pelo Basement são menores que as temperaturas encontradas nos métodos do GroundDomain e do SoilTemp, e que no inverno as temperaturas obtidas pelo Basement são maiores que nos demais modelos.

Tabela 9 - Condições máximas e mínimas de temperatura interna do ar e das interfaces solo/piso e solo/paredes

\begin{tabular}{|c|c|c|c|c|c|}
\hline \multirow{3}{*}{$\begin{array}{c}\text { Temperatura } \\
\text { externa máxima } \\
\text { do } \operatorname{ar}\left({ }^{\circ} \mathrm{C}\right)\end{array}$} & \multicolumn{5}{|c|}{ Temperatura interna máxima do ar no verão $\left({ }^{\circ} \mathrm{C}\right)$} \\
\hline & \multirow{2}{*}{ SoilTemp } & \multicolumn{3}{|c|}{ GroundDomain } & \multirow{2}{*}{ Basement } \\
\hline & & GDomain:FD & GDomain:KA & GDomain:Xing & \\
\hline 31,9 & 23,6 & 27,9 & 28,1 & 28,1 & 22,1 \\
\hline \multirow{3}{*}{$\begin{array}{c}\text { Temperatura } \\
\text { interna mínima } \\
\text { do ar }\end{array}$} & \multicolumn{5}{|c|}{ Temperatura interna mínima do ar no inverno $\left({ }^{\circ} \mathrm{C}\right)$} \\
\hline & \multirow{2}{*}{ SoilTemp } & \multicolumn{3}{|c|}{ GroundDomain } & \multirow{2}{*}{ Basement } \\
\hline & & GDomain:FD & GDomain:KA & GDomain:Xing & \\
\hline 6,7 & 15 & 11,1 & 11,3 & 11,4 & 16,3 \\
\hline \multicolumn{6}{|c|}{ Temperatura máxima nas interfaces no verão $\left({ }^{\circ} \mathrm{C}\right)$} \\
\hline \multirow{2}{*}{ Interfaces } & \multirow{2}{*}{ SoilTemp } & \multicolumn{3}{|c|}{ GroundDomain } & \multirow{2}{*}{ Basement } \\
\hline & & GDomain:FD & GDomain:KA & GDomain:Xing & \\
\hline piso/solo & não calculado & 24 & 24 & 24,3 & 17,8 \\
\hline paredes/solo & não calculado & 24 & 24,4 & 25,5 & 18,2 \\
\hline \multicolumn{6}{|c|}{ Temperatura mínima nas interfaces no inverno $\left({ }^{\circ} \mathrm{C}\right)$} \\
\hline \multirow{2}{*}{ Interfaces } & \multirow{2}{*}{ SoilTemp } & \multicolumn{3}{|c|}{ GroundDomain } & \multirow{2}{*}{ Basement } \\
\hline & & GDomain:FD & GDomain:KA & GDomain:Xing & \\
\hline piso/solo & não calculado & 14,8 & 15,1 & 14,1 & 17,4 \\
\hline paredes/solo & não calculado & 15,1 & 15,1 & 15,7 & 18,6 \\
\hline
\end{tabular}


Figura 7 - Variação de temperatura máxima do ar entre o Basement e os demais modelos

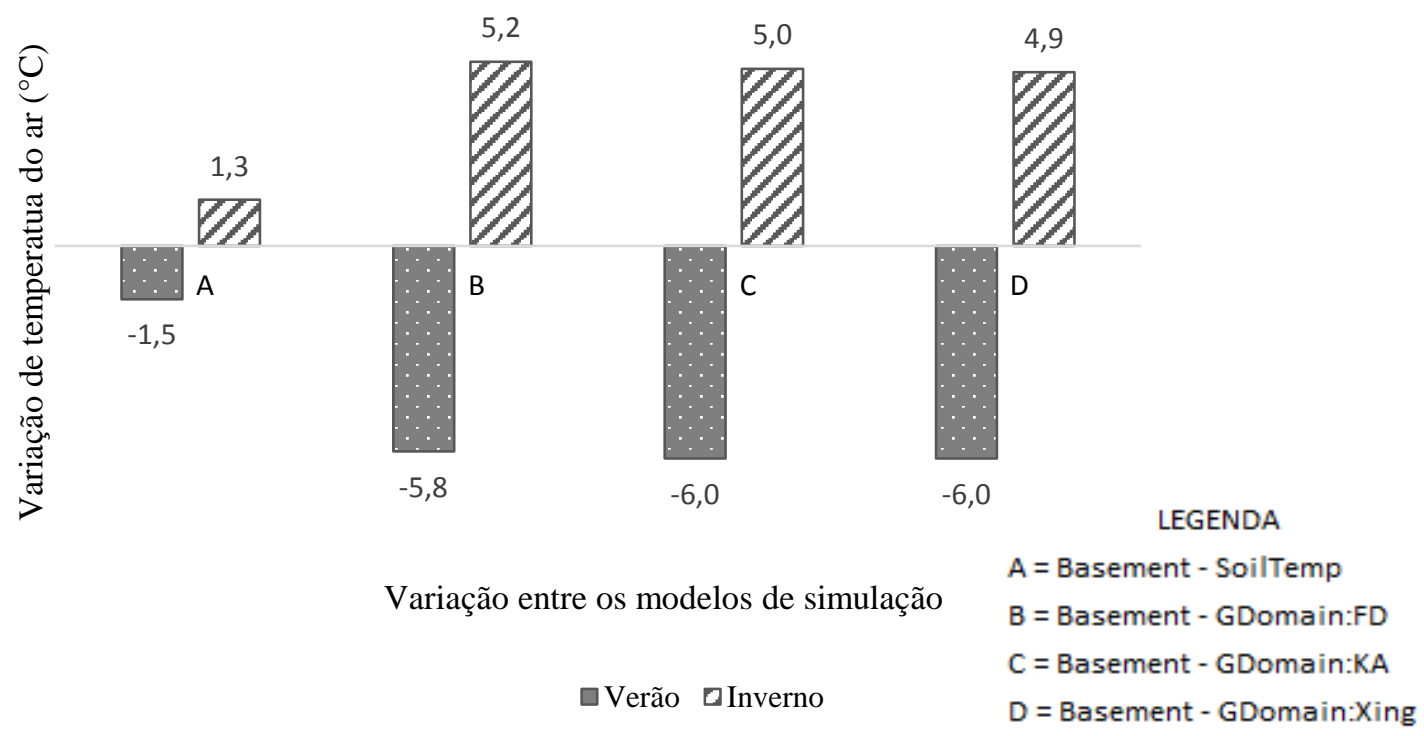

Os resultados obtidos para os modelos pertencentes ao objeto GroundDomain apresentam os valores mais extremos quando comparados aos resultados gerados pelo pré-processador Basement. Ao desenvolver uma análise de desempenho térmico com uma classificação intermediária ou superior, os resultados gerados pelo acionamento de qualquer modelo pertencente ao objeto GroundDomain poderão gerar dados que influenciem em práticas construtivas desnecessárias e energeticamente ineficientes, quando de fato a edificação analisada é satisfatória a essa classificação. Além disso, apesar de o modelo de simulação que desconsidera a influência do solo (SoilTemp) apresentar resultados muito próximos aos obtidos pelo pré-processador Basement, a comparação dos dois modelos não pode ser generalizada a todos os casos. Para a simulação do SoilTemp os dados informados são obtidos pelo arquivo climático, e, como as propriedades do solo variam muito com o tempo e dentro de uma mesma localidade, os resultados gerados por esse modelo não apresentam um grau de precisão satisfatório. Esses resultados demonstram o impacto considerável das alternativas de modelagem analisadas (FiniteDifference, KusudaAchenbach, Xing e Basement) na temperatura do ar interno, o que indica a importância da consideração do solo como um fator ativo nas análises de desempenho térmico.

\section{Resultados obtidos para o grupo de simulação 3}

Para verificar a influência do solo, são avaliadas as duas situações informadas na Tabela 3 com o objetivo de verificar se a modificação das propriedades termofísicas do solo causariam impacto na temperatura interna do ambiente subterrâneo. Todos os casos foram simulados utilizando-se o pré-processador Basement. Na Figura 8 indicam-se os resultados máximos de temperatura obtidos para a análise de um dia típico de verão e os resultados mínimos de temperatura interna obtidos para um dia típico de inverno.

No verão as menores temperaturas são obtidas para o solo argiloso seco, enquanto as temperaturas mais elevadas foram encontradas para a análise de um solo argiloso saturado. Os dados apresentados na Figura 8 indicam que a temperatura do ambiente subterrâneo chega a ser $0,6{ }^{\circ} \mathrm{C}(2,8 \%)$ mais elevada para um solo argiloso saturado quando comparado aos resultados gerados para o solo argiloso seco. Já no inverno essa variação de temperatura é insignificante (menor que $0,1 \%$ ). 
Figura 8 - Condições máximas e mínimas de temperatura interna

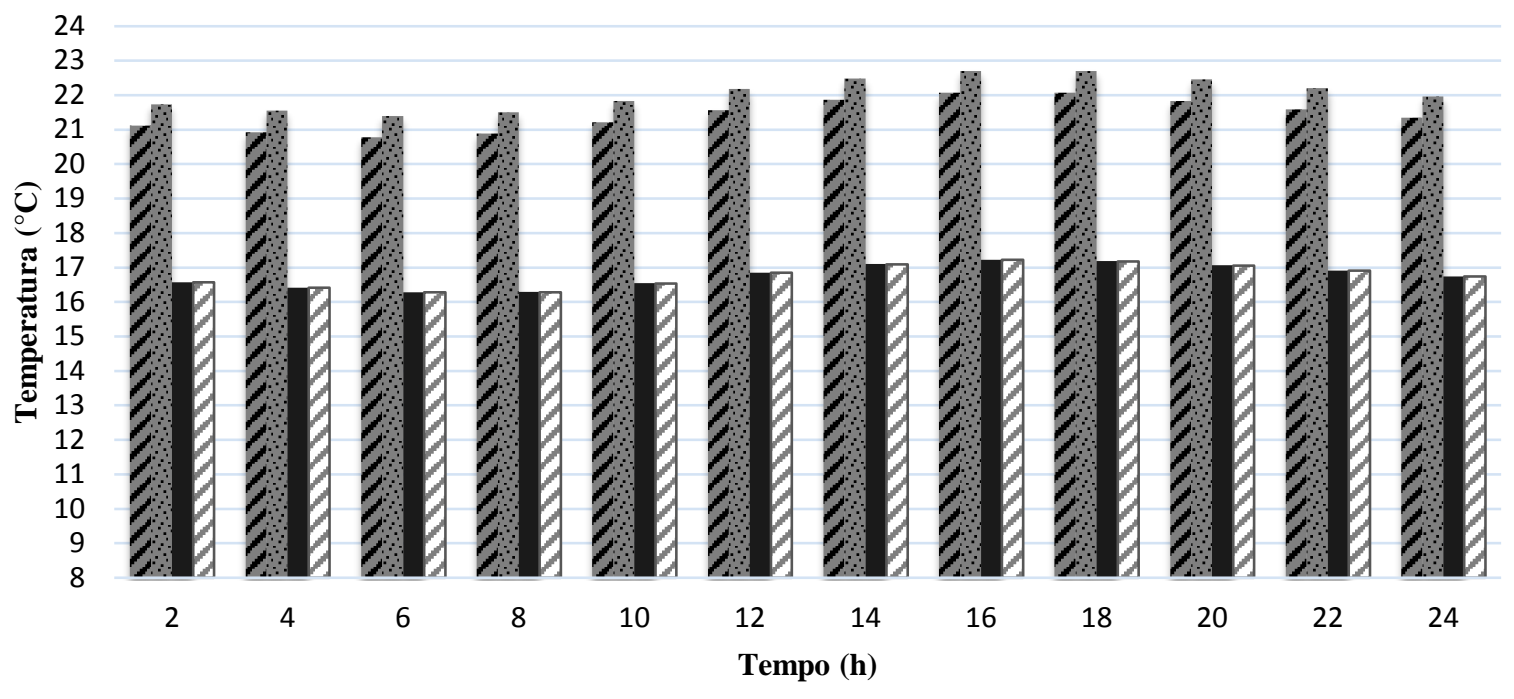

1 Solo Argiloso Seco: Verão

- Solo Argiloso Seco: Inverno s Solo Argiloso Saturado: Verão

$\square$ Solo Argiloso Saturado: Inverno

\section{Conclusões}

Este trabalho investigou a influência do solo no desempenho térmico de ambientes subterrâneos em uma edificação térrea naturalmente ventilada de São Paulo a partir de comparações realizadas entre simulações obtidas em que diferentes alternativas de modelagem existentes no programa EnergyPlus foram adotadas. A partir dos dados de entrada descritos nesta pesquisa é possível observar que o pré-processador Basement apresenta uma abordagem mais sofisticada em relação aos modelos do objeto GroundDomain. Além disso, possui uma formulação tridimensional, fato que o coloca à frente dos demais modelos. Sendo assim, os resultados indicaram que a desconsideração do pré-processador Basement gera uma diferença muito significativa em uma avaliação de desempenho térmico de ambientes de uma edificação que estão em contato com o solo. Quando não utilizado, a diferença de temperatura interna do ambiente subterrâneo gerou um acréscimo de até $6,7 \%\left(1,5^{\circ} \mathrm{C}\right)$ no verão e uma redução de até $8 \%\left(1,3^{\circ} \mathrm{C}\right)$ no inverno. Em relação aos modelos pertencentes ao GroundDomain, a variação de temperatura interna do ambiente subterrâneo chegou a ser $27 \%\left(6{ }^{\circ} \mathrm{C}\right)$ mais elevada no verão e até $32 \%\left(5,2{ }^{\circ} \mathrm{C}\right)$ menos elevada no inverno quando comparada aos resultados apresentados pelo Basement. Comparando-se os resultados desta pesquisa com os obtidos por Kharrufa (2008), ainda é possível verificar que a variação encontrada entre a temperatura externa do ar e a interna foi de $8{ }^{\circ} \mathrm{C}$ para a edificação de Bagdá, enquanto para a edificação de São Paulo essa variação foi de $9,8^{\circ} \mathrm{C}$ para o modelo Basement e de $3,8-4^{\circ} \mathrm{C}$ para os modelos do GroundDomain. Esses dados fornecem indicações de que um comportamento semelhante para condições de construção parecidas com a adotada neste trabalho é obtido neste artigo.

Apesar de as simulações não utilizarem dados medidos in loco, os resultados indicaram que a variação do tipo do solo e principalmente sua consideração nas análises geraram impacto na temperatura interna do ambiente subterrâneo. A variação do grau de saturação do solo argiloso resultou em temperaturas 2,8\% $\left(0,6{ }^{\circ} \mathrm{C}\right)$ mais elevadas para a consideração do solo saturado em relação ao solo seco no verão, enquanto no inverno a variação das propriedades termofísicas do solo não influenciou nos resultados de temperatura interna. Esses dados indicam que em uma análise precisa de desempenho térmico condizente com a realidade, tanto por meio do EnergyPlus quanto por meio de outros softwares de simulação energética, a consideração do solo como um meio ativo no processo de transferência de calor é necessária para que o conforto térmico dos ocupantes seja ponderado de forma correta.

Quanto ao critério de desempenho térmico estabelecido pela norma 15575 (ABNT, 2013) para a ventilação natural, com uma taxa de renovação de ar de $1 \mathrm{Ren} / \mathrm{h}$, em ambas as situações, verão e inverno, a edificação térrea de São Paulo é satisfatória aos resultados apresentados para que o desempenho mínimo seja alcançado, sendo que o 
ambiente subterrâneo apresentou nível de desempenho superior da norma para as simulações em que o Basement foi adotado. Entretanto, é possível observar que nas simulações em que o GroundDomain é utilizado esse nível de desempenho superior não é atingido. Consequentemente, a desconsideração do Basement pode gerar análises equivocadas de desempenho térmico em que uma classificação inapropriada é realizada.

A complexidade dos modelos mais completos, como o Basement, e a falta de informações sobre os dados do solo são aspectos que acabam restringindo o uso dessas ferramentas computacionais ao meio científico e acadêmico ou até mesmo desencorajando a consideração da influência do solo em muitas análises de desempenho. Entretanto, os resultados obtidos nesta pesquisa indicam a importância da consideração do solo como um fator influente no desempenho térmico de uma edificação e que a escolha por determinado método de simulação pode influenciar nas práticas construtivas adotadas em fase de projeto.

Essas conclusões indicam uma grande necessidade de se conhecer melhor o tema investigado e, por meio de comparações com dados reais, definir o processo de cálculo que melhor representa a realidade, pois há incertezas em diversos dos dados de entrada. Além disso, a validação desses modelos é realizada para países que possuem um clima adverso ao clima brasileiro, o que gera dúvidas quanto a seu correto funcionamento, uma vez que não existem pesquisas correlatas a título de comparação realizadas no Brasil. Os resultados obtidos neste estudo de caso também se limitaram à análise de dias típicos de projeto, de verão e de inverno, sendo interessante que futuros trabalhos avaliem a simulação anual, adotando como base condições climáticas típicas ou normais, e não condições extremas, caracterizadas pelos dias típicos de projeto.

\section{Referências}

AMERICAN SOCIETY OF HEATING, REFRIGERATING AND AIR CONDITIONING ENGINEERS. ANSI/ASHRAE Standard 140-

2001: standard method of test for the evaluation of building energy analysis computer programs. Atlanta, 2014.

ANDOLSUN, S. et al. EnergyPlus vs. DOE-2.1e: the effect of ground-coupling on energy use of a code house with basement in a hot-humid climate. Energy and Buildings, v. 43, p. 1663-1675, 2011.
ASSOCIAÇÃO BRASILEIRA DE NORMAS TÉCNICAS. NBR 15220-2: desempenho térmico de edificações: parte 2: métodos de cálculo da transmitância térmica, da capacidade térmica, do atraso térmico e do fator solar de elementos e componentes de edificações. Rio de Janeiro, $2005 a$.

\section{ASSOCIAÇÃO BRASILEIRA DE NORMAS}

TÉCNICAS. NBR 15220-3: desempenho térmico de edificações: parte 3: zoneamento bioclimático brasileiro e estratégias de condicionamento térmico passivo para habitações de interesse social. Rio de Janeiro, 2005b.

\section{ASSOCIAÇÃO BRASILEIRA DE NORMAS}

TÉCNICAS. NBR 15575: edificações

habitacionais: desempenho. Rio de Janeiro, 2013.

\section{BAHNFLETH, W. P. Three-Dimensional} Modelling of Heat Transfer From Slab Floors. Urbana, 1989. 214 f. Tese (Doutorado de Filosofia em Engenharia Mecânica) - University of Illinois, Urbana, 1989.

BRASIL. Ministério da Agricultura. Centro Nacional de Ensino e Pesquisas Agronômicas. Serviço Nacional de Pesquisas Agronômicas. Comissão de Solos. Levantamento de Reconhecimento dos Solos do Estado de São Paulo: contribuição à carta de solos do Brasil. Rio de Janeiro, 1960.

BRITO, A. C. Contribuição da Inércia Térmica na Eficiência Energética de Edifícios de Escritórios na Cidade de São Paulo. São Paulo, 2015. 241 f. Tese (Doutorado em Engenharia) Escola Politécnica, Universidade de São Paulo, São Paulo, 2015.

CLEMENTS, E. Three Dimensional Foundation Heat Transfer Modules For Whole-Building Energy Analysis. Pennsylvania, 2004. 133 f. Tese (Doutorado em Ciências) - Pennsylvania State University, Pennsylvania, 2004.

COGIL, C. A. Modeling of Basement Heat Transfer and Parametric Study of Basement Insulation For Low Energy Housing.

Pennsylvania, 1998. Tese (Doutorado em Ciências) - Pennsylvania State University, Pennsylvania, 1998.

COSTA, V. A. C. da; RORIZ, V. F.; CHVATAL, K. M. S. Modeling of Slab-on-Grade Heat Transfer in EnergyPlus Simulation Program. Ambiente Construído, Porto Alegre, v. 17, n. 3, p. 117-135, jul./set. 2017. 
DEPARTMENT OF ENERGY EFFICIENCY AND RENEWABLE ENERGY. Basement.

2016b. Disponível em:

$<$ https://energyplus.net/downloads $>$. Acesso em: 10 out. 2017.

DEPARTMENT OF ENERGY EFFICIENCY AND RENEWABLE ENERGY. EnergyPlus.

Version 8.6.0. 2016a. Disponível em:

$<$ https://energyplus.net/downloads>. Acesso em: 10 out. 2017.

DEPARTMENT OF ENERGY EFFICIENCY

AND RENEWABLE ENERGY. Engineering

Reference. US. Documentation, EnergyPlusTM Version 8.6, 2016c.

\section{DEPARTMENT OF ENERGY EFFICIENCY}

AND RENEWABLE ENERGY. Ground Heat Transfer in EnergyPlus. Documentation, EnergyPlusTM Version 8.6, Auxiliary Programs, p. 103-142, 2016d.

DEPARTMENT OF ENERGY EFFICIENCY AND RENEWABLE ENERGY. Input Output

Reference. US. Documentation, EnergyPlusTM Version 8.6, 2016e.

HERB, W. R. et al. Ground Surface Temperature Simulation For Different Land Covers. Journal of Hydrology, Minneapolis, v. 356, p. 327-343, 2008.

KHARRUFA, S. Evaluation of Basement's Thermal Performance in Iraq For Summer Use. Journal of Asian Architecture and Building Engineering, Ajman, v. 7, p. 411-417, 2008.

KRARTI, M. Ground-Coupled Heat Transfer: a chapter in advances in solar energy. ASES Publication, p. 90, 1999.

KUSUDA, T.; ARCHENBACH, P. Earth Temperature and Thermal Diffusivity at Selected Stations in the United States. ASHRAE

Transaction, v. 71, n. 1, p. 61-75, 1965.

LABS, K. et al. Building Foundation Design

Handbook. The Center, p. 349, ORNL/Sub/8672143/1, 1988.

LEE, E. S. An Improved Hydronic Loop System Solution Algorithm With a Zone-Coupled Horizontal Ground Heat Exchanger Model For Whole Building Energy Simulation. Oklahoma, 2013. 325 f. Tese (Doutorado em Filosofia) Oklahoma State University, Oklahoma, 2013.
MAZZAFERRO, L.; MELO, A. P.; LAMBERTS, R. Manual de Simulação Computacional de Edifícios Com o Uso do Objeto Ground Domain no Programa EnergyPlus. Florianópolis, 2015.

MORSELLI, T. B. G. A. Biologia do Solo.

Pelotas: UFPel, 2009.

OKE, T. R. Boundary Layer Climates. $2^{\text {nd }}$. ed. London: British Library, 1995.

SHIPP, P. H.; PFENDER, E.; BLIGH, T. P. Thermal Characteristics of a Large Earth Sheltered Building (Parts 1 and 2). Underground Spaces 6, p. 53-64, 1981.

SILVA, A. S. et al. Incerteza do Método de Simulação da NBR 15575-1 Para a Avaliação do Desempenho Térmico de Habitações. Ambiente Construído, Porto Alegre, v. 14, n. 4, p. 103-117, out./dez. 2014.

SORGATO, M. J. et al. Análise do Procedimento de Simulação da NBR 15575 Para Avaliação do Desempenho Térmico de Edificações Residenciais. Ambiente Construído, Porto Alegre, v. 14, n. 4, p. 83-101, out./dez. 2014.

SOUZA, H. A. de; AMPARO, L. R.; GOMES, A. $P$. Influência da Inércia Térmica do Solo e da Ventilação Natural no Desempenho Térmico: um estudo de caso de um projeto residencial em light steel framing. Ambiente Construído, Porto Alegre, v. 11, n. 4, p. 113-128, out./dez. 2011.

UNITED STATES DEPARTMENT OF ENERGY. Energy Plus Simulation Software. 2016. Disponível em:

$<$ https://energyplus.net/weather>. Acesso em: 31 jan. 2018.

XING, L. U. Estimations of Undisturbed Ground Temperatures Using Numerical and Analytical Modeling. Stillwater, 2014. 406 f. Tese (Doutorado em Filosofia) - Oklahoma State University, Stillwater, 2014.

ZAKI, H.; AL-MUSAED, A. A.; KHALIL, A. Thermal Earth Inertia Such a Source of Energy For Bio-Sustainable House. In: WORLD SUSTAINABLE BUILDING CONFERENCE, 5., Tokyo, 2005. Proceedings... Tokyo, 2005.

\section{Agradecimentos}

Os autores agradecem à Fundação Capes e à Fapemig por financiarem esta pesquisa. 


\section{Bruna Cristina Resende}

Programa de Pós-Graduação em Engenharia Civil, Escola de Minas | Universidade Federal de Ouro Preto | Morro do Cruzeiro, s/ $\mathrm{n}$ | Ouro Preto - MG - Brasil | CEP 35400-000 | Tel.: (32) 99904-0604 | E-mail: brunacresende@yahoo.com.br

\section{Henor Artur de Souza}

Programa de Pós-Graduação em Engenharia Civil, Escola de Minas | Universidade Federal de Ouro Preto | Tel.: (31) $3559-1533$ Ramal 1482 | E-mail: henorster@gmail.com

\section{Adriano Pinto Gomes}

CODADES | Instituto Federal de Minas Gerais | Rua Pandiá Calógeras, 898, Campus Ouro Preto | Ouro Preto - MG - Brasil | CEP $35400-000$ | Tel.: (31)3559 2277| E-mail: adriano.gomes@ifmg.edu.br

\section{Revista Ambiente Construído}

Associação Nacional de Tecnologia do Ambiente Construído

Av. Osvaldo Aranha, 99 - 3o andar, Centro

Porto Alegre - RS - Brasil

CEP 90035-190

Telefone: +55 (51) 3308-4084

Fax: +55 (51) 3308-4054

www. seer. ufrgs. br/ ambienteconstruido

E-mail: ambienteconstruido@ufrgs.br

(c) (i)

This is an open-access article distributed under the terms of the Creative Commons Attribution License. 